Supporting Information for:

\title{
Synthesis, Optimization and Performance Demonstration of Electrospun Carbon Nanofiber-Carbon Nanotube Composite Sorbents for Point-of-Use Water Treatment
}

Katherine T. Peter, ${ }^{1}$ John D. Vargo, ${ }^{2}$ Thilini P. Rupasinghe, ${ }^{3}$ Aribet De Jesus, ${ }^{4}$ Alexei V. Tivanski, ${ }^{3}$ Edward A. Sander, ${ }^{4}$ Nosang V. Myung, ${ }^{5}$ and David M. Cwiertny ${ }^{1 *}$

${ }^{1}$ Department of Civil and Environmental Engineering, University of Iowa

${ }^{2}$ State Hygienic Laboratory, University of Iowa

${ }^{3}$ Department of Chemistry, University of Iowa

${ }^{4}$ Department of Biomedical Engineering, University of Iowa

${ }^{5}$ Department of Chemical and Environmental Engineering, University of California, Riverside

Prepared April 18, 2016

ACS Applied Materials \& Interfaces

1 Table, 21 Figures, and 29 Pages

*Corresponding author contact information:

Phone: +1-319-335-1401; Fax: +1-319-335-5660;

Email: david-cwiertny@uiowa.edu;

Mail: Department of Civil and Environmental Engineering

4105 Seamans Center, Iowa City, IA 52242 


\section{Materials and Methods}

Reagents. All reagents were used as received. Electrospinning precursor solutions were prepared with polyacrylonitrile (PAN; MW 150,000, Aldrich), N,N-dimethylformamide (DMF; 99.85\%, BDH Chemicals), terephthalic acid (99+\%, Acros Organics), phthalic acid (99.5+\%, Aldrich), and multi-wall carbon nanotubes (MWCNTs; $95+\%$, ash $<1.5 \mathrm{wt} \%,<8 \mathrm{~nm}$ OD, $0.5-2.0$ $\mu \mathrm{m}$ length, CheapTubes). Stock solutions of atrazine (Pestanal ${ }^{\circledR}$, analytical standard, Fluka, Sigma), bezafibrate ( $\geq 98 \%$, Sigma), caffeine (ReagentPlus $®$, Sigma), (-)-cotinine ( $\geq 98 \%$, Sigma), gemfibrozil (Sigma), metoprolol tartrate (LKT laboratories), naproxen (meets USP testing specifications, Sigma), sulfadimethoxine ( $\geq 98.5 \%$, Sigma), and sulfamethoxazole (Fluka, Sigma) were prepared in methanol (99.99\%, Fisher Scientific). Structures and relevant molecular data for these compounds are compiled in Table S1. Sorption experiments were conducted either in $5 \mathrm{mM}$ phosphate buffer (anhydrous potassium phosphate monobasic, $\mathrm{KH}_{2} \mathrm{PO}_{4}$; RPI; ACS grade) or $1 \mathrm{mM}$ carbonate buffer (anhydrous sodium carbonate, $\mathrm{Na}_{2} \mathrm{CO}_{3}$; Fisher Scientific, ACS grade) prepared from deionized water (Thermo Scientific Barnstead NANOPure Diamond) and $\mathrm{pH}$-adjusted as needed with $5 \mathrm{M} \mathrm{NaOH}$. Granular activated carbon (GAC) was acquired from the Calgon Carbon Corporation (CENTAUR ${ }^{\circledR} 12 \times 40$; Iodine number $825 \mathrm{mg} / \mathrm{g}$; Mean particle diameter 0.9-1.1 mm; Ash $<7 \mathrm{wt} \%$ ).

Electrospinning Protocol. After preparation and prior to use, the kinematic viscosity of select sol gels was estimated by measuring the time for a set volume of sol gel to flow by gravity through a fixed length of tubing. The precursor solutions were then loaded into a $12 \mathrm{~mL}$ plastic syringe (HSW Norm-Ject). The syringe was connected to $2.0 \mathrm{~mm}$ ID polyethylene (PE) tubing via a PE 1/16" female luer lock fitting (NanoNC Co., Ltd). The tubing was also connected to a metal nozzle adapter (NanoNC Co., Ltd) via a PE 1/16" male luer lock fitting, and a 25G 1/2" needle was attached to the other end of the nozzle adapter. The needle tip was located at a distance of $10 \mathrm{~cm}$ from the surface of a 9-5/16"-circumference metal drum collector (SPG Co., Ltd; Korea), which was coated in $\mathrm{Al}$ foil and grounded. During electrospinning, the precursor solution was pumped through the needle at $0.5 \mathrm{~mL} / \mathrm{h}$ (New Era Pump Systems, Inc.), a positive $12 \mathrm{kV}$ voltage was applied at the needle tip (Acopian), and the grounded collector was rotating at 500-rpm (Dingtuo Technology). The high voltage difference between needle tip and collector caused formation of a whipping polymer jet, evaporation of the solvent, and deposition of nonwoven polymer (or polymer CNT composite) nanofibers on the collector surface.

Instrumentation for Nanofiber Characterization. The morphology of electrospun nanofiber mats was investigated using a field-emission scanning electron microscope (SEM) (S4800, Hitachi) at an acceleration voltage of $1.8 \mathrm{kV}$. All samples were sputter-coated with a thin layer of gold/palladium (60:40 Au:Pd) prior to SEM imaging. Average fiber diameters were developed from measurement of 50-100 nanofibers in ImageJ software. Morphology of selected mats was also examined using transmission electron microscopy (TEM) (JEOL JEM-1230) at an operating voltage of $120 \mathrm{kV}$, as well as using high resolution transmission electron microscopy (HRTEM) (JEOL JEM 2100F with Schottky FEG Emission-Zr/W). Samples were prepared via sonication in deionized water, and a droplet was allowed to dry on a grid prior to imaging 
(\#01814-F C-B 400 mesh Cu for TEM, \#01824 UC-A on holey 400 mesh Cu for HR-TEM; Ted Pella, Inc). Surface area and pore volumes were determined by $\mathrm{N}_{2}$-BET analysis using a Micromeritics ASAP 2020 Physisorption Analyzer. All samples were degassed at $300^{\circ} \mathrm{C}$ for 3 hours prior to analysis. Surface composition was analyzed with a custom Kratos Axis Ultra Xray photoelectron spectroscopy (XPS) system equipped with a monochromatic Al K $\alpha$ X-ray source. XPS was used to collect full spectrum survey scans, as well as to examine $\mathrm{C} 1 \mathrm{~s}, \mathrm{O} 1 \mathrm{~s}$, and N 1s regions. An extensive description of this system can be found elsewhere. ${ }^{1,2}$

Strength Analysis Procedures. The mechanical strength of nanofibers and nanofiber mats was characterized by two complementary methods. The goal of characterization was to develop a quantitative assessment of the influence of CNT inclusion and macroporosity on nanofiber strength.

Atomic Force Microscopy Nanoindentation. The mechanical strength of individual nanofibers was characterized using atomic force microscopy (AFM) based nanoindentation conducted on a Molecular Force Probe 3D AFM (Asylum Research, Santa Barbara, CA). ${ }^{3-5}$ AFM height images and nanoindentation measurements were performed at room temperature in air, using silicon nitride probes (Mikromasch, San Jose, CA, CSC37) with a nominal spring constant of $0.35 \mathrm{~N} / \mathrm{m}$ and a typical tip radius of curvature of $10 \mathrm{~nm}$. The tip radius of curvature was verified using scanning electron microscopy (SEM) and was found to be approximately 10 $\mathrm{nm}$, as expected. Actual spring constants were determined using the built-in thermal noise method. ${ }^{6}$ Topographic images were collected using intermittent contact mode (AC mode) or contact mode at a typical scan rate of $1 \mathrm{~Hz}$. Nanofiber mat samples were adhered to freshly cleaved atomically flat mica (V-I grade, SPI Supplies, Westchester, PA) using double-sided tape, and topographic images were obtained prior to nanoindentation experiments using AC imaging mode. For nanoindentation measurements, force-displacement curves were collected during the AFM probe motion towards and away from the sample. The probe was initially $200 \mathrm{~nm}$ away from the surface, was moved towards the nanofiber surface until a predetermined force of $10 \mathrm{nN}$ was achieved, and then the applied force was reversed until the probe returned to the initial position. A maximum force of $10 \mathrm{nN}$ was selected because no sign of mechanical damage on the sample surface has been observed under such conditions after a series of repeated forcedisplacement measurements in previous studies. ${ }^{3,4}$ In order to ensure reproducibility, repeated force curves ( $\sim 10$ curves) were collected at a minimum of 5 sampling locations per nanofiber for 10 individual nanofibers within each mat. Force-displacement curves were also collected on the mica substrate in order to calibrate the deflection sensitivity of the instrument, which allowed the conversion of the force-displacement curves to force versus tip-sample separation plots. Overall, 4 different probes were used for the nanoindentation measurements.

Young's modulus values were extracted from force versus tip-sample separation data by fitting nanoindentation plots to a rearranged form of the Hertzian model, which assumes elastic contact. ${ }^{5,7,8}$ All force-displacement plots herein showed no deviation between the approach data and the retract data. Thus the indentation could be assumed purely elastic, allowing use of the Hertzian elastic model. The Hertzian model is described by Equation S1 below, where F is the 
loading force, $\mathrm{R}$ is the tip radius of curvature, $\Delta$ is the tip-sample separation, $\mathrm{E}$ is the Young's modulus, $\mathrm{C}$ is a constant, and $v$ is the Poisson's ratio of the sample. Use of this rearranged form eliminated the necessity of knowing the exact contact position between the tip and the sample, which is typically challenging. ${ }^{9}$ Based on Equation S1, a plot of the force to the $2 / 3$ power vs. the tip-sample separation should be linear in the contact region. The Young's modulus of the sample can then be calculated using the linear slope of the $\mathrm{F}^{2 / 3} \mathrm{vs} . \Delta$ plot in the contact region, with known or reported values of the tip radius of curvature and the Poisson's ratio. Here, $\mathrm{R}$ and $v$ were assumed to be $10 \mathrm{~nm}$ (using SEM) and 0.3 (typical value for organic nanomaterials), respectively. ${ }^{4}$ An average Young's modulus ( \pm one standard deviation) for each nanofiber sample was obtained from histograms of Young's modulus values (provided below in Figure S8a).

$$
\mathrm{F}^{2 / 3}=\mathrm{C}-\left(\frac{4 \sqrt{\mathrm{R}}}{3\left(1-\mathrm{v}^{2}\right)} \mathrm{E}\right)^{2 / 3} \Delta
$$

Load-Displacement Testing. Stress-strain curves were also developed for select nanofiber mats from load-displacement data collected with a BioTense Perfusion Bioreactor (ADMET, Inc., Norwood, MA), which consisted of a linear actuator, sample grips, a reactor frame, and a $250 \mathrm{~g}$ load cell (see Figure S8b). Data acquisition was performed at $10 \mathrm{samples} / \mathrm{sec}$ through the MTestQuattro System (ADMET, Inc., Norwood, MA). Unlike the AFM-based nanoindentation performed on individual nanofibers within a mat, this load-displacement technique provided a measure of the average mechanical properties of the bulk nanofiber mat. Dog-bone-shaped specimens (with a gauge region measuring $2 \mathrm{~mm}$ wide by $8 \mathrm{~mm}$ long) were cut out using a stainless steel punch. The specimens were clamped to the sample grips with flat alligator clips, the initial gap between the arms was measured with calipers and recorded, and the position and the load were zeroed. Specimens were stretched to failure at a displacement rate of $10 \mathrm{~mm} / \mathrm{min}$, with the maximum extension set to $4 \mathrm{~mm} .{ }^{10}$ Cross-sectional images of the mat in the gauge region were taken with a microscope (Nikon Eclipse Ti with Plan Fluor 4x objective), and the average thickness of the mat was determined via measurement with Image $\mathrm{J}$ software to allow the cross-sectional area of the specimen to be quantified. Engineering strain was calculated as the change in position during the test $\left(1-1_{0}\right)$ divided by the gauge length $(\mathrm{L})$, and stress was calculated as the recorded load (F) during the test divided by the initial cross-sectional area (A) of the gauge region. The Young's modulus was calculated from the slope of the stress-strain curves (see Figure S8b). The ultimate tensile stress (UTS) and ultimate strain were calculated from the curve as the highest stress achieved before specimen failure and the corresponding strain, respectively.

Batch Sorption Experimental Details. Timescales necessary to achieve sorption equilibrium (i.e., no further change in solution phase concentration) were determined first via kinetic experiments conducted in $20 \mathrm{~mL}$ vials sealed with butyl stoppers. Each vial contained 15 $\mathrm{mL}$ of $5 \mathrm{mM}$ phosphate buffer solution adjusted to $\mathrm{pH} 7$ and a sorbent (e.g., nanofiber mat or GAC) at a mass loading at $0.5 \mathrm{~g} / \mathrm{L}$. Reactors were spiked at the start of the experiment with either $50 \mu \mathrm{M}$ of atrazine (ATZ) or sulfamethoxazole (SMX) from $50 \mathrm{mM}$ stock solutions prepared in methanol (which produced $<10^{-3} \% \mathrm{v} / \mathrm{v} \mathrm{MeOH}$ in the final reactor suspension). 
Reactors were well-mixed throughout the experiment on a rotator (Cole-Palmer Roto-Torque). Samples were taken periodically and then passed through a $0.2 \mu \mathrm{m}$ Nylon syringe filter to remove the sorbent material. Controls containing no sorbent were conducted in parallel to reactors with nanofiber mats to account for any inadvertent losses via sorption to the vial stopper and/or syringe filter during equilibration and sample processing. After filtration, samples were transferred to $1.5 \mathrm{~mL}$ amber vials for subsequent analysis via high pressure liquid chromatography equipped with a photodiode array detector (HPLC-DAD).

Sorption isotherms were collected in batch experiments performed in well-mixed reactors similar to those used for kinetic experiments. The sorbent mass loading was held constant ( 0.4 $\mathrm{g} / \mathrm{L})$. Reactors were spiked at the start of the experiment with varying concentrations (13-170 $\mu \mathrm{M}$ ) of ATZ or SMX from $50 \mathrm{mM}$ stock solutions prepared in methanol (resulting in $<3.4 \times 10^{-3}$ $\% \mathrm{v} / \mathrm{v} \mathrm{MeOH}$ in the final reactor suspension). Based on results from kinetic experiments, isotherm samples were taken at 0 and $6 \mathrm{~h}$ for nanofiber mats and after $24 \mathrm{~h}$ for GAC. Samples were then passed through a $0.2 \mu \mathrm{m}$ Nylon syringe filter to remove the sorbent material. Sample post-processing and analysis was identical to that performed for kinetic sorption experiments. Batch $\mathrm{pH}$-edge experiments were also performed in identical reactors, with $0.4 \mathrm{~g} / \mathrm{L}$ sorbent mass loading, $70 \mu \mathrm{M}$ initial concentration SMX or metoprolol, $5 \mathrm{mM}$ phosphate buffer ( $\mathrm{pH}$ 6-9), and sample post-processing and analysis identical to that for sorption isotherm experiments.

Analytical methods. High concentration $(>0.1 \mathrm{mg} / \mathrm{L})$ aqueous samples from batch experiments were analyzed on a 1200 series Agilent HPLC equipped with an Eclipse Plus C18 column (4.6 mm x $150 \mathrm{~mm}, 5 \mu \mathrm{m}$ particle size) and a photodiode array detector (DAD). Analysis of ATZ used a mobile phase of 50:50 acetonitrile $(\mathrm{ACN}): \mathrm{H}_{2} \mathrm{O}$, a flow rate of $1 \mathrm{~mL} / \mathrm{min}$, an injection volume of $20 \mu \mathrm{L}$, and a $223 \mathrm{~nm}$ detection wavelength, whereas SMX analysis used a 30:70 ratio of methanol $(\mathrm{MeOH}): 5 \mathrm{mM}$ phosphate buffer $\mathrm{pH}$, a flow rate of $1 \mathrm{~mL} / \mathrm{min}$, an injection volume of $25 \mu \mathrm{L}$, and a $268 \mathrm{~nm}$ detection wavelength. Samples with lower concentration ( $5 \mu \mathrm{g} / \mathrm{L}$; i.e., those used in single-target, flow-through systems) were analyzed via HPLC-MS/MS, with a 1200 series Agilent HPLC equipped with an Eclipse Plus C18 column (4.6 mm x $150 \mathrm{~mm}, 5 \mu \mathrm{m}$ particle size) and a QQQ detector (Agilent 6460 Triple Quad LC/MS). Analysis of ATZ was performed via a MS2 SIM method, with a mobile phase of 50:50 ACN: $\mathrm{H}_{2} \mathrm{O}$, a flow rate of $0.4 \mathrm{~mL} / \mathrm{min}$, an injection volume of $5 \mu \mathrm{L}$, and a parent compound mass of 216, whereas SMX analysis was performed via a MS2 SIM method, with a mobile phase of $30: 70 \mathrm{MeOH}: \mathrm{H}_{2} \mathrm{O}$, a flow rate of $0.4 \mathrm{~mL} / \mathrm{min}$, an injection volume of $5 \mu \mathrm{L}$, and a parent compound mass of 254 .

Aqueous samples of the mixture of 10 emerging contaminants utilized in low concentration $(5 \mu \mathrm{g} / \mathrm{L})$ flow-through systems were analyzed at the University of Iowa State Hygienic Laboratory via direct aqueous injection LCMSMS. Samples were injected $(100 \mu \mathrm{L})$ into an Agilent 1200 HPLC system operated in a reversed phase mode (acetonitrile, methanol, water, acetic acid gradient) using a Phenomenex Luna C18(2) column ( $3 \mu \mathrm{m}, 3.0 \times 100 \mathrm{~mm})$. A turbospray interface (ESI) was used to generate positive and negative molecular ions which were subsequently fragmented and monitored using an AB Sciex 4000 QT LCMSMS system. Ions 
were monitored in the MRM mode. Unique quantitative and qualitative ion pair fragments were monitored. Internal standard, containing a mixture of labeled analytes, was added to each sample just prior to analysis at a concentration equal to that in the calibration standards $(0.5 \mathrm{ng} / \mathrm{mL})$. Labeled analytes were used as internal standards to correct for instrument signal drift and/or matrix effects. The following analytes (internal standard use in parenthesis) were monitored as positive ions: acetaminophen (acetaminophen-D4), caffeine (caffeine-13C3), cotinine (caffeine13C3), metoprolol (metoprolol-D7), sulfadimethoxine (sulfamethoxazole-13C6), sulfamethoxazole (sulfamethoxazole-13C6), and atrazine (atrazine-D5). The following analytes (internal standard use in parenthesis) were monitored as negative ions: gemfibrozil (diclofenacD4), naproxen (diclofenac-D4), and bezafibrate (diclofenac-D4). External calibration was used for quantitation (quadratic curve fit with $1 / \mathrm{x}$ weighting). Calibration standards ranged in concentration from 0.005 to $10 \mathrm{ng} / \mathrm{mL}$ for each analyte. Random samples were spiked with known amounts of the target analytes just prior to analysis to assess the accuracy of the method. 


\section{Results and Discussion}

Table S1. Structures, molecular weights, $\log K_{\text {ow }}$ values $^{11}$ and relevant $\mathrm{p} K_{\mathrm{a}}$ values $^{12}$ for the ten organic micropollutants treated in the multi-contaminant flow-through system.

\begin{tabular}{|c|c|c|c|c|}
\hline Compound & Structure & $\begin{array}{c}\text { Molecular } \\
\text { Weight }\end{array}$ & $\log K_{\mathrm{ow}}$ & $\mathrm{p} K_{\mathrm{a}}$ \\
\hline Caffeine & & 194.19 & -0.07 & \\
\hline Cotinine & & 176.22 & 0.07 & 4.36 \\
\hline Acetaminophen & & 151.16 & 0.46 & 9.48 \\
\hline Sulfamethoxazole & & 253.28 & 0.89 & 9.28 \\
\hline Sulfadimethoxine & & 310.33 & 4.63 & 6.36 \\
\hline Metoprolol & & 267.36 & 1.88 & 9.09 \\
\hline Atrazine & & 215.68 & 2.61 & \\
\hline
\end{tabular}




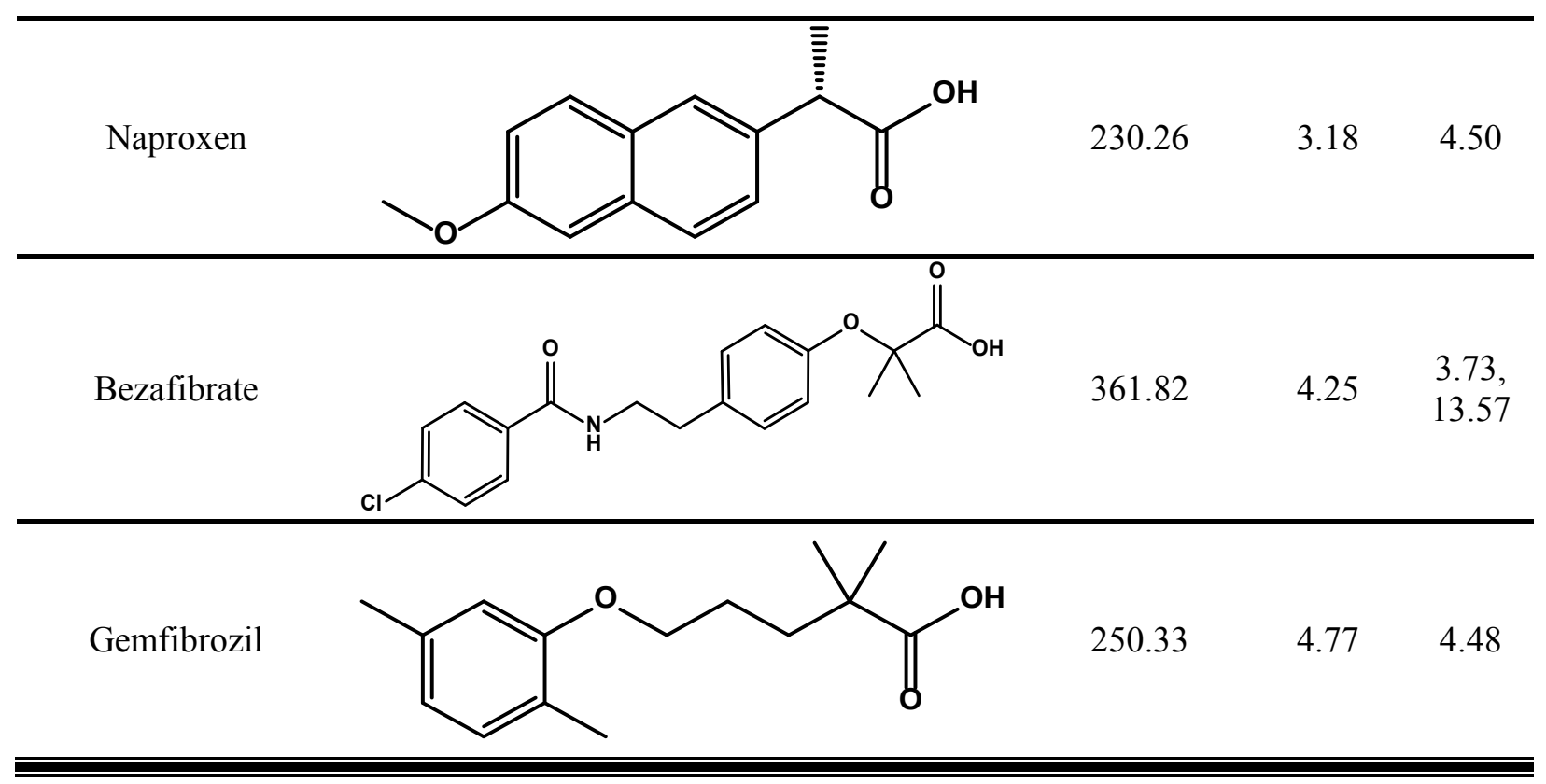



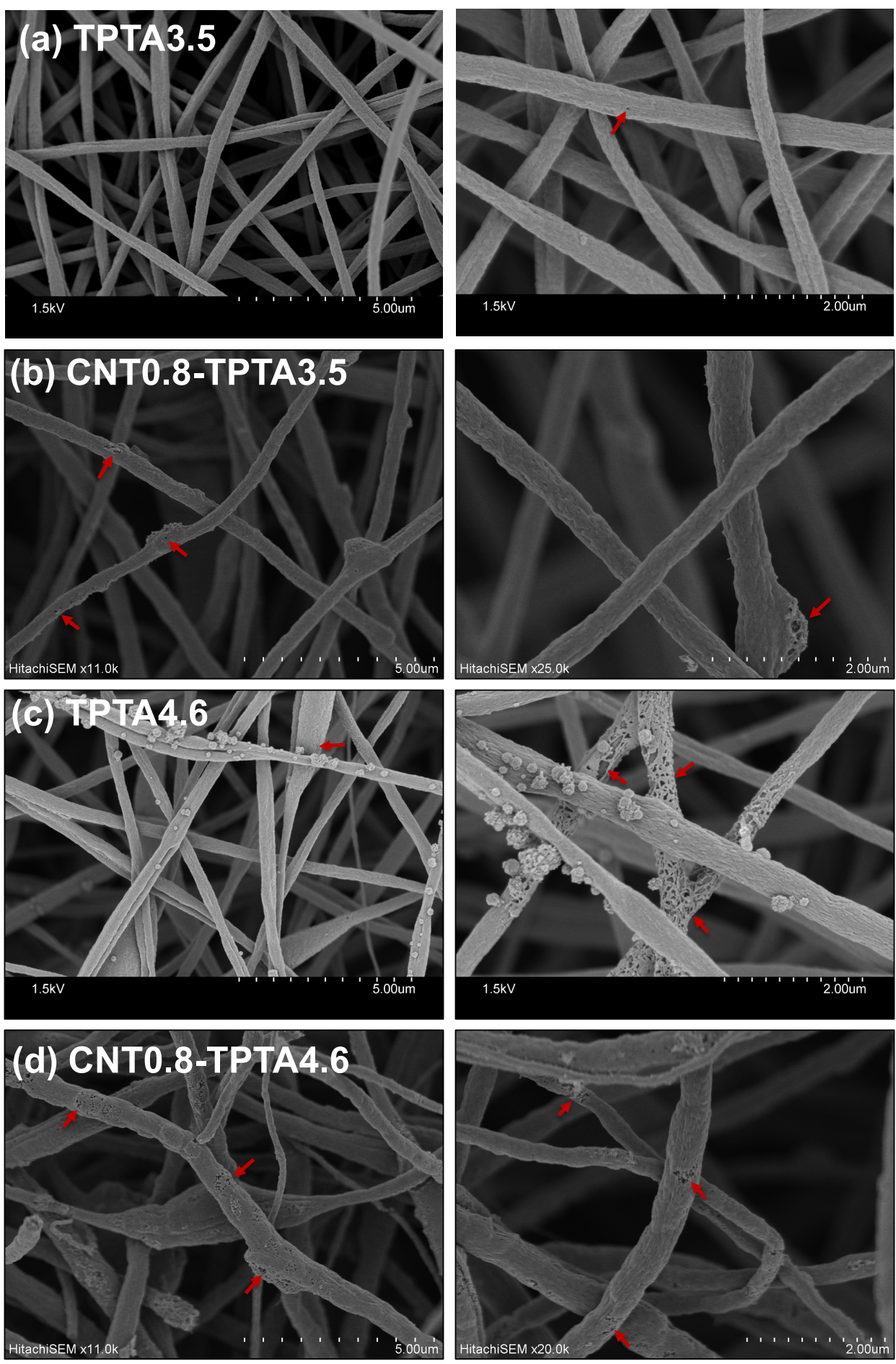

Figure S1. SEM images of TPTA-containing CNFs (a, c) and TPTA-containing CNF-CNT composites $(\mathrm{b}, \mathrm{d})$ for both low $(3.5 \mathrm{wt} \%)$ and high $(4.6 \mathrm{wt} \%)$ TPTA loadings. Materials shown contain low (0.8 wt\%) CNT loading. Both CNT-derived morphology (e.g., knobs) and TPTAderived morphology (e.g., macropores) are marked by red arrows. Consistent with prior results of Liu et al., ${ }^{13}$ we found that increasing concentrations of TPTA yielded a higher degree of macroporosity. 


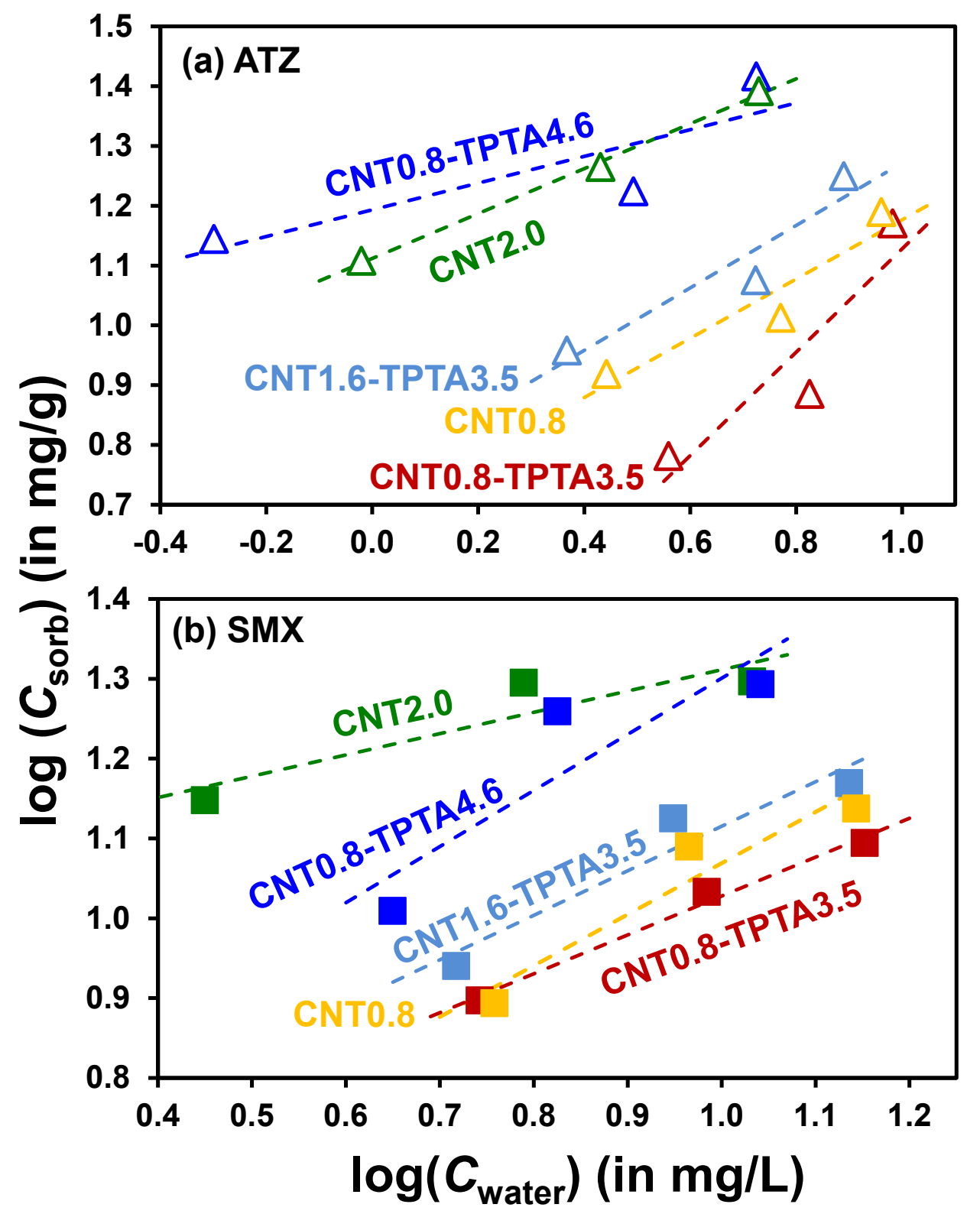

Figure S2. Data shown for (a) ATZ and (b) SMX uptake by TPTA-containing CNF-CNT composites, relative to CNF-CNT composite materials. Consistent with the literature, ${ }^{13}$ we found that TPTA could be incorporated to yield a mat more flexible than unmodified CNFs. However, like PTA modified materials, TPTA modified mats were very poor sorbents (data not shown). Further, at the high TPTA and CNT concentrations needed for appreciable ATZ and SMX uptake during sorption isotherm experiments, we encountered both fabrication challenges (e.g., clogging during electrospinning) and unacceptable material properties (e.g., weak mats that could not be folded without breaking). Because of their fabrication challenges and poor material strength, mats containing TPTA-derived macroporosity were not further investigated. Experimental conditions: $0.4 \mathrm{~g} / \mathrm{L}$ nanofiber sorbent, $5 \mathrm{mM}$ phosphate buffer, $\mathrm{pH} 7$. 

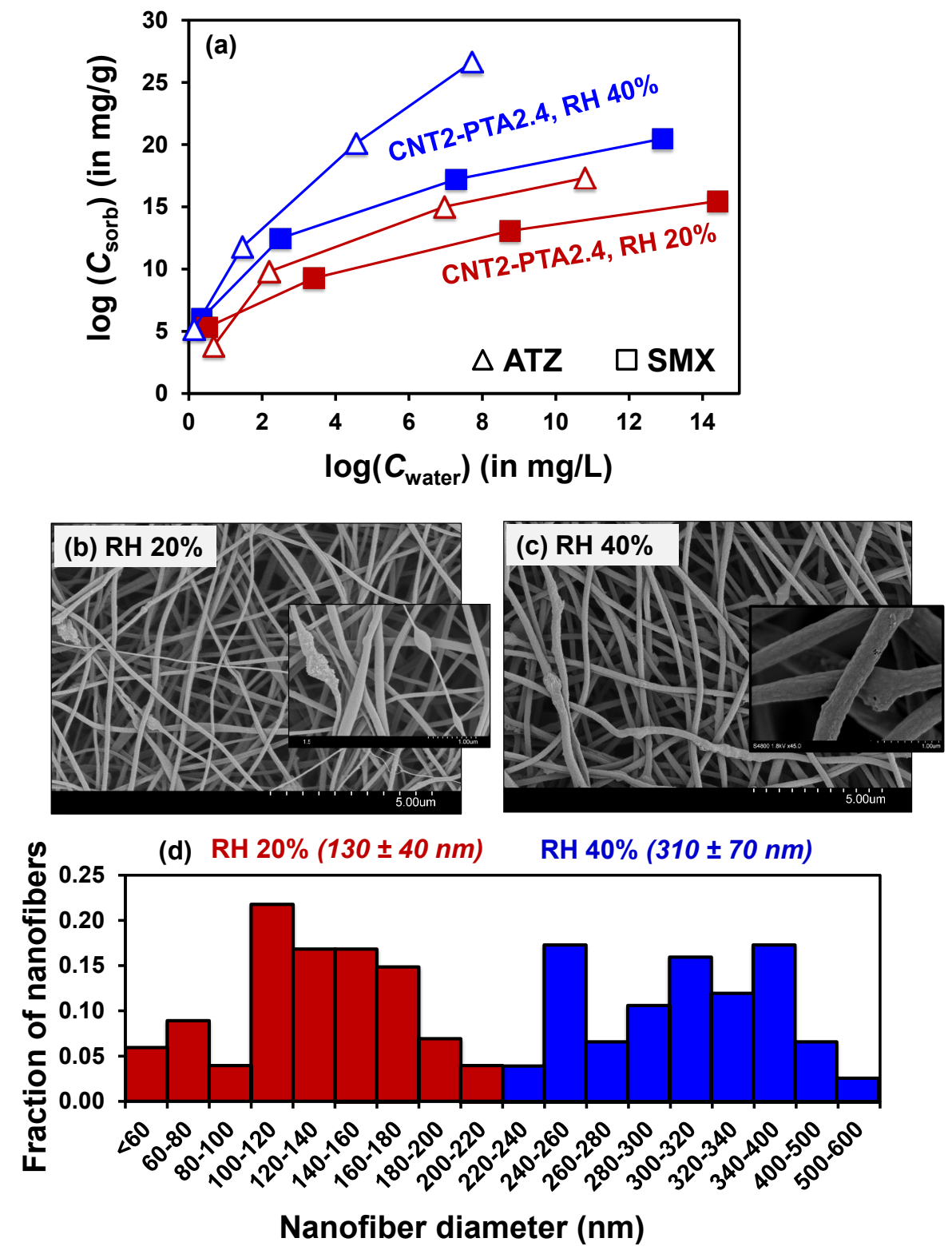

Figure S3. Nanofiber sorbents were fabricated at low and high relative humidity ( $\sim 20 \%$ and $\sim 40 \%$, respectively). Shown here are the effect of relative humidity during electrospinning on (a) sorption isotherms for ATZ and SMX $(0.4 \mathrm{~g} / \mathrm{L}$ sorbent loading, $5 \mathrm{mM}$ phosphate buffer, $\mathrm{pH}$ 7), $(b, c)$ nanofiber morphology, and (d) nanofiber diameter distribution (obtained via measurement of 50-100 nanofibers in ImageJ software). The production of smaller nanofiber diameters at lower humidity is in agreement with the literature. ${ }^{14}$ We hypothesize that the more rough (porous) appearance of the nanofibers fabricated at higher humidity (see inset SEM images) is due to the expulsion of water from the nanofiber matrix during thermal treatment steps. Thus, despite larger nanofiber diameters, the surface roughness generated at higher humidity yielded nanofibers with larger sorption capacities for both ATZ and SMX. Based on higher material capacity at higher relative humidity, the majority of materials in this study were fabricated at $\sim 40 \%$ relative humidity. 

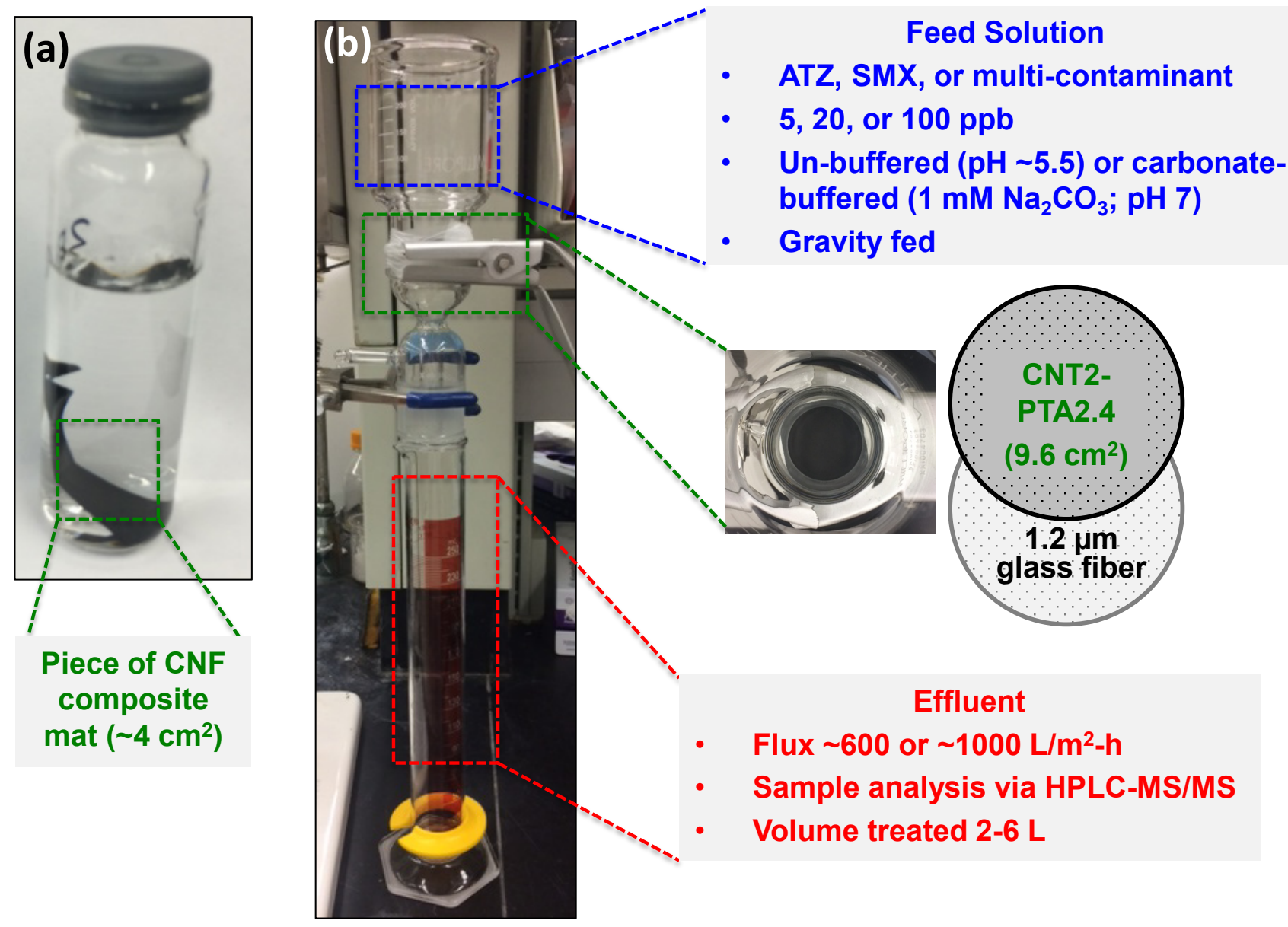

Figure S4. (a) Batch reactor for kinetic and isotherm studies, which used a cohesive piece ( $\sim 4$ $\mathrm{cm}^{2}$ ) of nanofiber mat rather than dispersed nanofibers. (b) The set-up for flow-through filtration studies, using a gravity-fed, 47-mm OD filter housing and a $1.2 \mu \mathrm{m}$ glass fiber filter support. Relevant experimental parameters are provided. To determine approximate filter capacity, initial trial runs were conducted with relatively high concentration $(20 \mu \mathrm{g} / \mathrm{L}$ or $100 \mu \mathrm{g} / \mathrm{L})$ feed solutions of either ATZ or SMX. Feed solutions were un-buffered to avoid counter-ion effects and to facilitate analysis via LC-MS/MS without buffer ion interference. Filter mass was varied by changing the thickness of the nanofiber mat. Mat mass loading was calculated as the total mass of the carbon filter normalized to the active area of filtration $\left(9.6 \mathrm{~cm}^{2}\right)$. The typical mat produced in this study had a mass loading of $14 \mathrm{mg}\left(1.5 \mathrm{mg} / \mathrm{cm}^{2}\right)$, and was compared to a low mat mass loading of $5 \mathrm{mg}\left(0.5 \mathrm{mg} / \mathrm{cm}^{2}\right)$ by utilizing a shorter electrospinning time. 


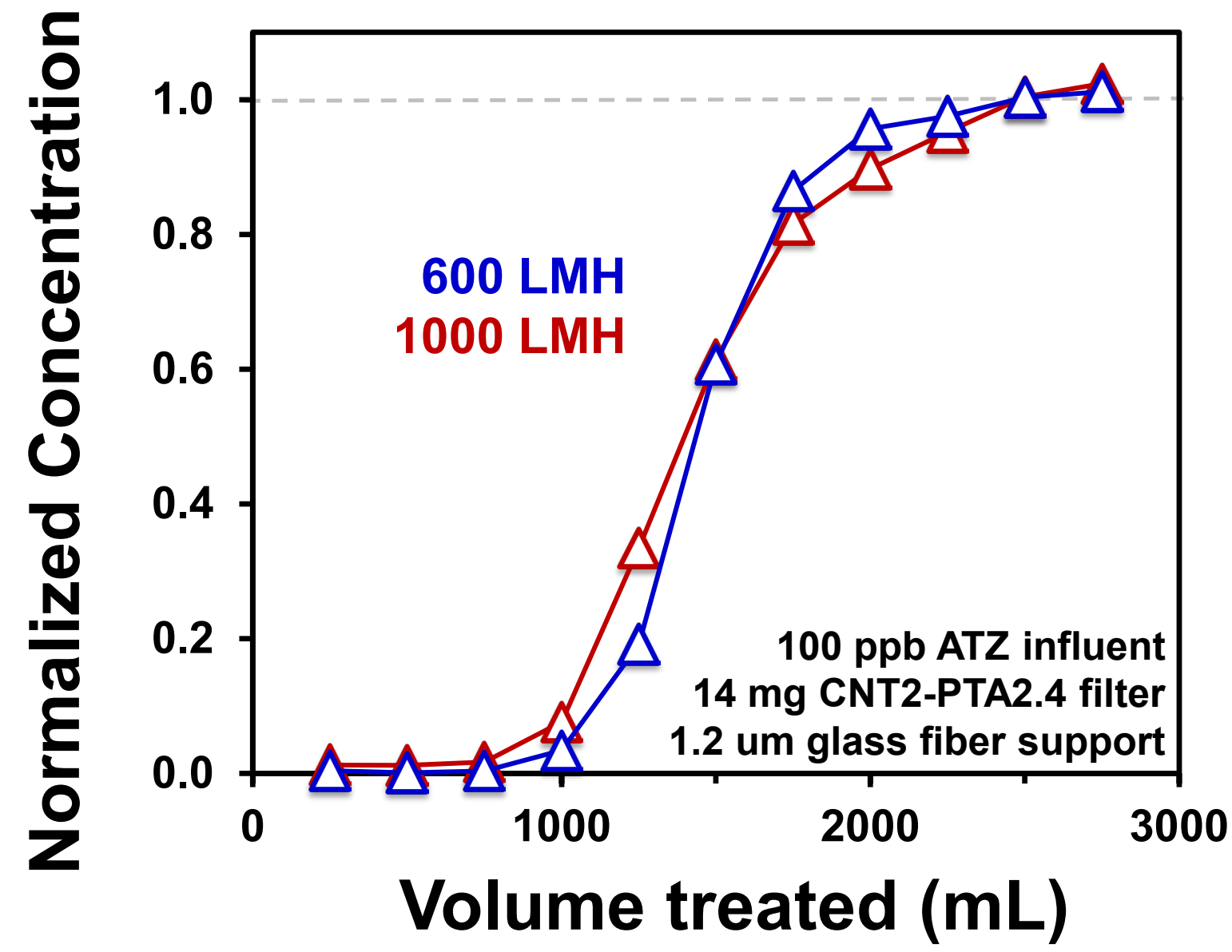

Figure S5. Effect of flux (600 vs. $1000 \mathrm{LMH}$ ) on breakthrough curves for removal of $100 \mathrm{ppb}$ $(100 \mu \mathrm{g} / \mathrm{L}) \mathrm{ATZ}$ in DI water by a $1.5 \mathrm{mg} / \mathrm{cm}^{2}$ CNT2-PTA2.4 filter. Flux was slowed from 1000 LMH to $600 \mathrm{LMH}$ by maintaining a lower head of influent above the filter. The effect of flux was found to be negligible in the single-filter flow-through system evaluated in this study, presumably due to a minimal change in contact time. For example, based on filter thicknesses evaluated during load cell testing, the slower flux would be expected to increase contact time within the filter by approximately half of a millisecond. Larger filter thicknesses or significantly larger differences in flux are likely necessary to truly elucidate the impact of contact time on removal. Thus, in the remainder of this study, flux was typically $\sim 1000 \mathrm{~L} / \mathrm{m}^{2}-\mathrm{h}$, to achieve the upper bound of typical microfiltration. 


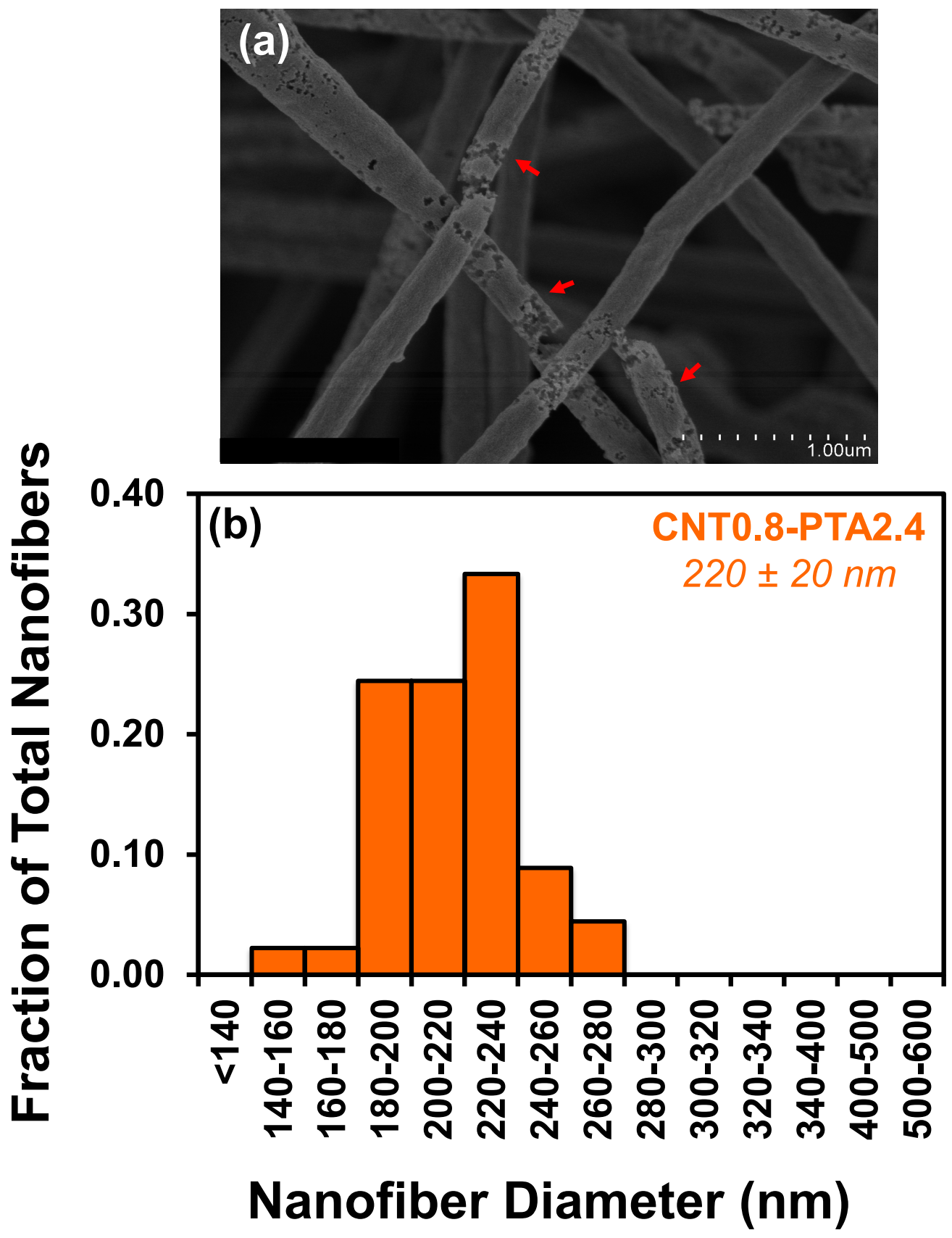

Figure S6. (a) Representative SEM image and (b) nanofiber diameter distribution for CNT0.8PTA2.4 material. Average nanofiber diameter (from $n$ of at least 50 nanofibers) was $220 \pm 20$ $\mathrm{nm}$. Red arrows in SEM image highlight the porosity introduced via sublimation of PTA. The higher macroporosity of these nanofibers relative to the high CNT, high PTA mat (CNT2PTA2.4) is notable. We attribute this to the ability of PTA to sublime more completely from these smaller diameter (and thus higher surface area) nanofibers, which results from their lower viscosity sol gel at lower CNT concentration. It is also possible that some PTA may be sorbed onto CNTs, and thus unavailable for sublimation, at higher CNT concentrations. 

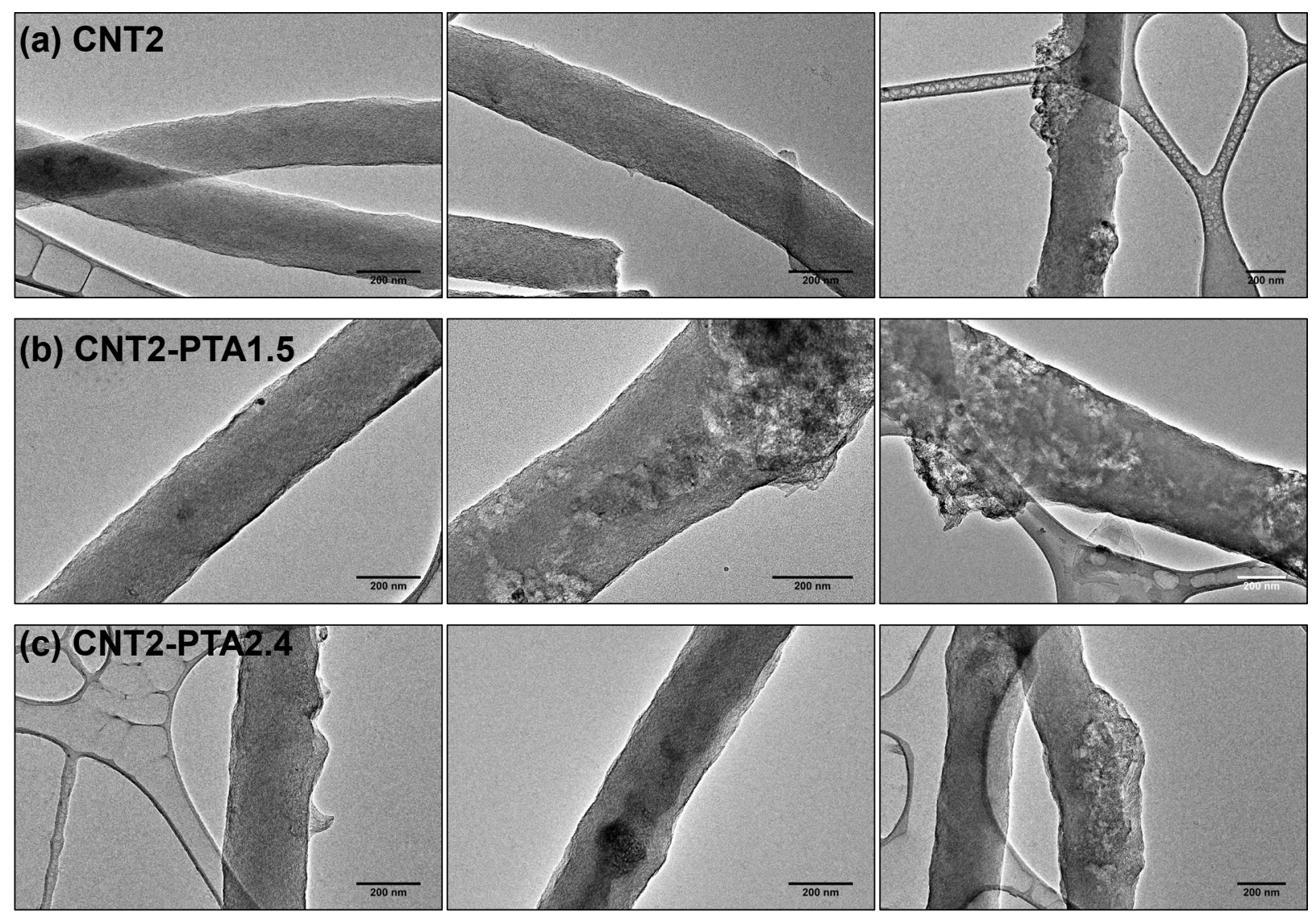

Figure S7. HRTEM images of (a) CNT2, (b) CNT2-PTA1.5, and (c) CNT2-PTA2.4. Images revealed similar morphology to those observed via SEM and TEM images. Due to the small size of CNTs used in the composite materials ( $<8 \mathrm{~nm}$ OD, $0.5-2.0 \mu \mathrm{m}$ length) relative to the nanofiber diameters (hundreds of $\mathrm{nm}$ ), CNTs are generally only visible via HRTEM when present as aggregated bundles. The images shown for each composite illustrate nanofiber segments both with and without clearly visible CNTs. We note the extreme macroporosity of the CNT2-PTA1.5 material is also clearly visible in (b). 

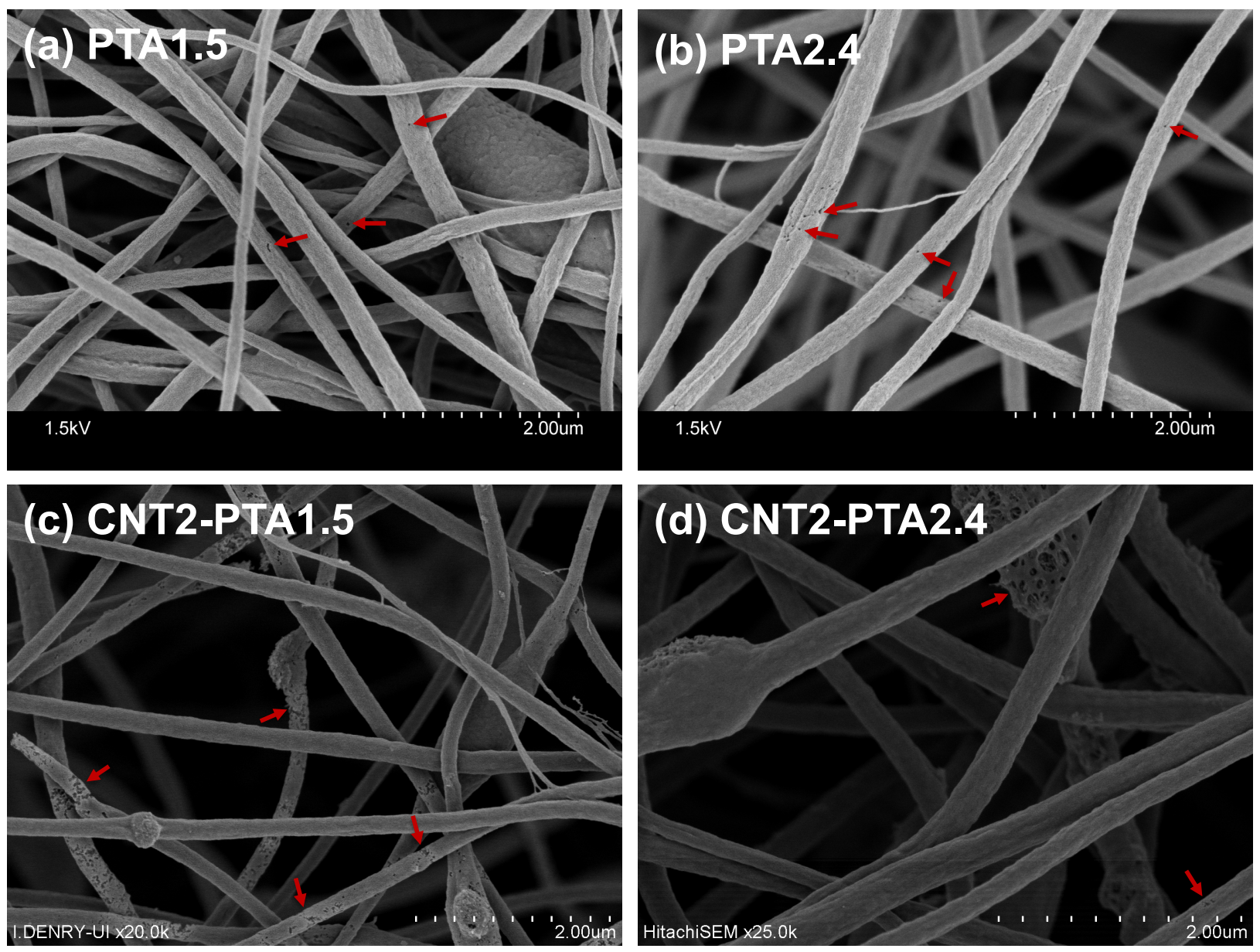

Figure S8. SEM images for PTA-containing CNFs $(a, b)$ and PTA-containing CNF-CNT composites (c,d). Images are shown for (a) PTA1.5, (b) PTA2.4, (c) CNT2-PTA1.5 and (d) CNT2-PTA2.4. In all images, macropores are indicated by red arrows. In line with TPTAderived macroporosity (see Figure S1 above), we found that increasing PTA concentration yielded a higher degree of macroporosity in PTA-only materials, albeit to a less extent. However, this trend was reversed in PTA-containing CNF-CNT composites, suggesting an influence of CNT and PTA interactions on macropore evolution. As evidence in support of such interactions, we measured $\sim 50 \mu \mathrm{g} / \mathrm{mg}$ of PTA uptake on CNTs in electrospinning solutions (in experiments examining changes in PTA UV/vis absorbance over time when in contact with CNTs in DMF). 


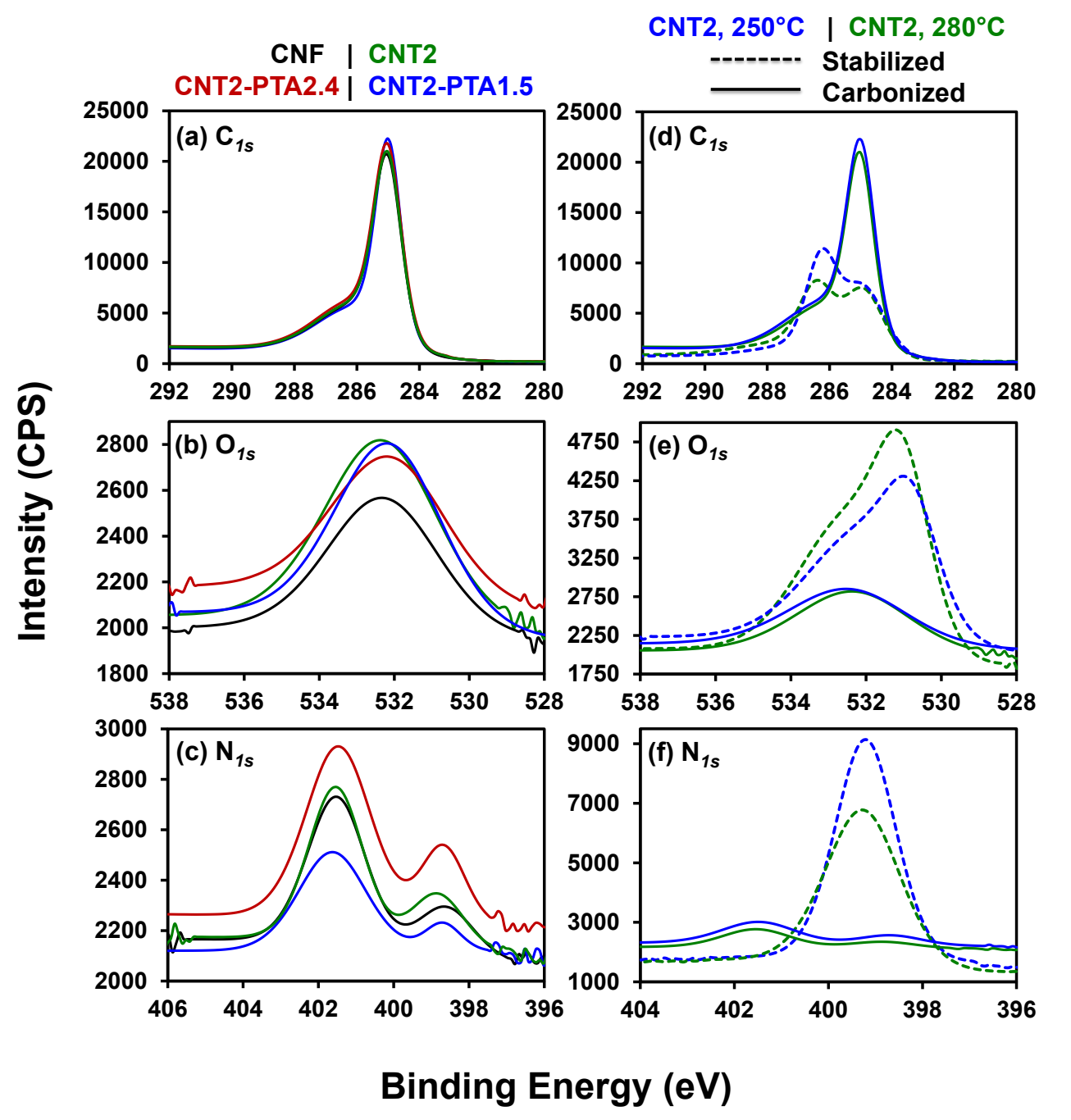

Figure S9. XPS core level (a) $\mathrm{C}_{1 \mathrm{~s}}$, (b) $\mathrm{O}_{1 \mathrm{~s}}$, and (c) $\mathrm{N}_{1 \mathrm{~s}}$ scans for carbonized CNF, CNT2, CNT2PTA2.4, and CNT2-PTA1.5 mats that were stabilized at $280^{\circ} \mathrm{C}$. XPS core level (d) $\mathrm{C}_{1 \mathrm{~s}}$, (e) $\mathrm{O}_{1 \mathrm{~s}}$, and (f) $\mathrm{N}_{1 \mathrm{~s}}$ scans for CNT2 mats stabilized at $250^{\circ} \mathrm{C}$ and $280^{\circ} \mathrm{C}$, both post-stabilization and postcarbonization. During thermal stabilization of CNT2 samples in air, the $\mathrm{N}_{1 \mathrm{~s}}$ peak at $399.2 \mathrm{eV}$ was consistent with partial conversion of nitrile $(C \equiv N)$ groups to imine $(C=N)$ and nitroso $(N=O)$ bonds, due to cyclization of PAN to produce a ladder structure. ${ }^{15,16}$ While trends in $\mathrm{C}$ and $\mathrm{N}$ content were comparable across stabilization temperatures $\left(250\right.$ and $\left.280^{\circ} \mathrm{C}\right)$, XPS suggested the introduction of more surface oxygen groups (e.g., hydroxyl, carbonyl, nitroso from the $\mathrm{O}_{1 \mathrm{~s}}$ region) at higher stabilization temperatures $\left(6.6 \% \mathrm{O}\right.$ at $250^{\circ} \mathrm{C}$ vs. $9.9 \% \mathrm{O}$ at $\left.280^{\circ} \mathrm{C}\right) .{ }^{16}$ After carbonization, the $\mathrm{C}_{1 \mathrm{~s}}$ peak was centered at $285 \mathrm{eV}$ (C-C bonds), indicative of PAN conversion to carbon, while the $\mathrm{N}_{1 \mathrm{~s}}$ region indicated the presence of primarily nitrile $(398.6 \mathrm{eV})$ and nitroso $(401.5 \mathrm{eV})$ functionalities. However, both the $\mathrm{N}$ and $\mathrm{O}$ contents of the carbonized CNT2 mats were comparable, regardless of stabilization temperature $(2 \% \mathrm{O}$ and $3 \% \mathrm{~N})$. Relatively modest differences were observed in surface $\mathrm{N}$ and $\mathrm{O}$ concentrations of CNF, CNT2, CNT2-PTA2.4, and CNT2-PTA1.5 mats stabilized at the same temperature. The surface oxygen concentration of CNT2-PTA2.4 was slightly higher than other materials $(2.7 \% \mathrm{O}$ vs. $2 \% \mathrm{O})$, while surface nitrogen content of CNT2-PTA1.5 was approximately half that of the other materials $(1.5 \% \mathrm{~N}$ vs. $3 \% \mathrm{~N})$. 

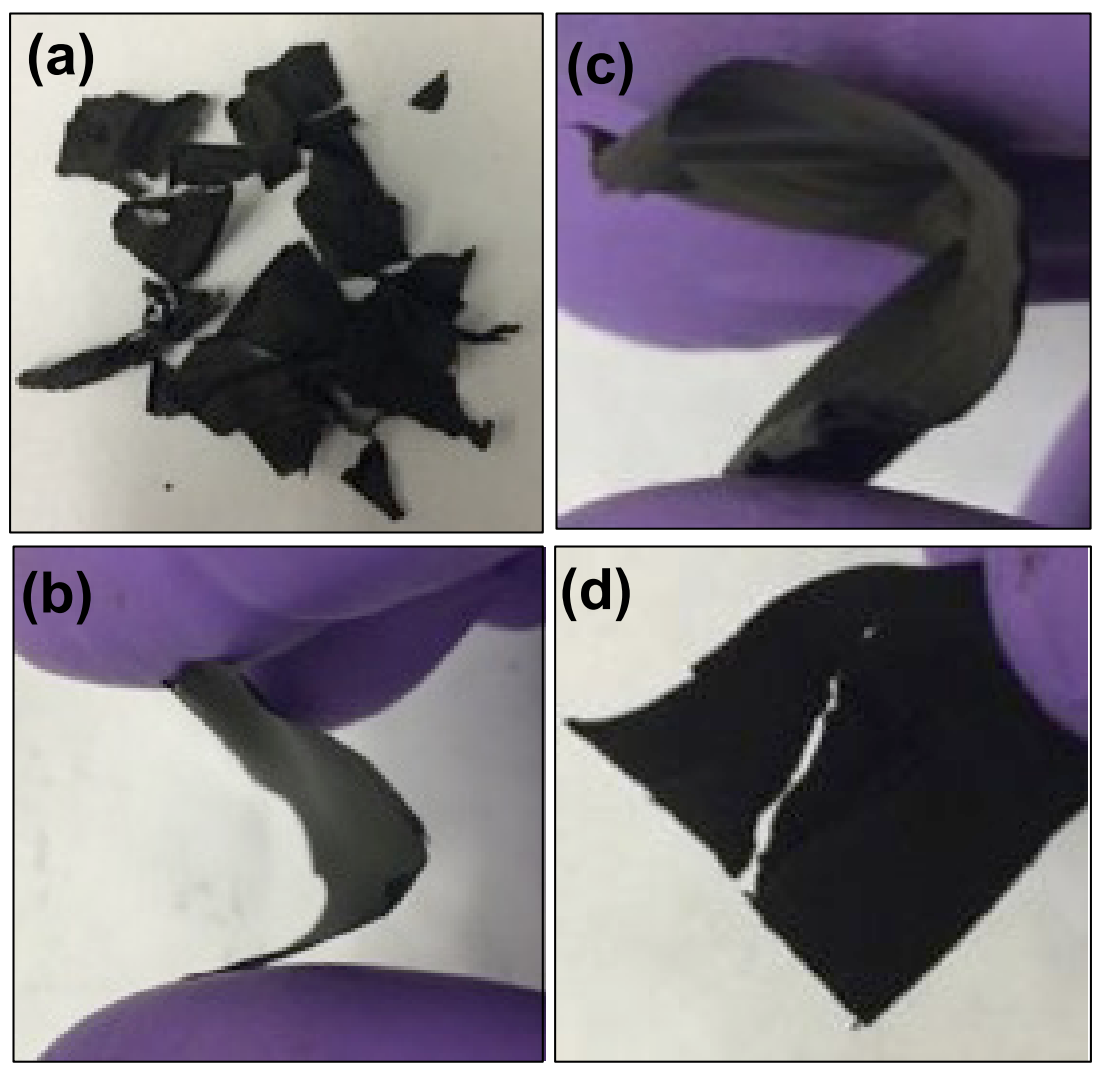

Figure S10. Qualitative assessments of nanofiber mat strength were made by examining their durability during and after basic handling procedures (e.g., gently folding the mats). Digital images from these assessments are shown for (a) CNF, (b) CNT2, (c) CNT2-PTA2.4, and (d) CNT2-PTA1.5 nanofiber mats. CNF readily broke into pieces owing to its extremely brittle nature. The tear in the CNT2-PTA1.5 resulted from folding of the material. 

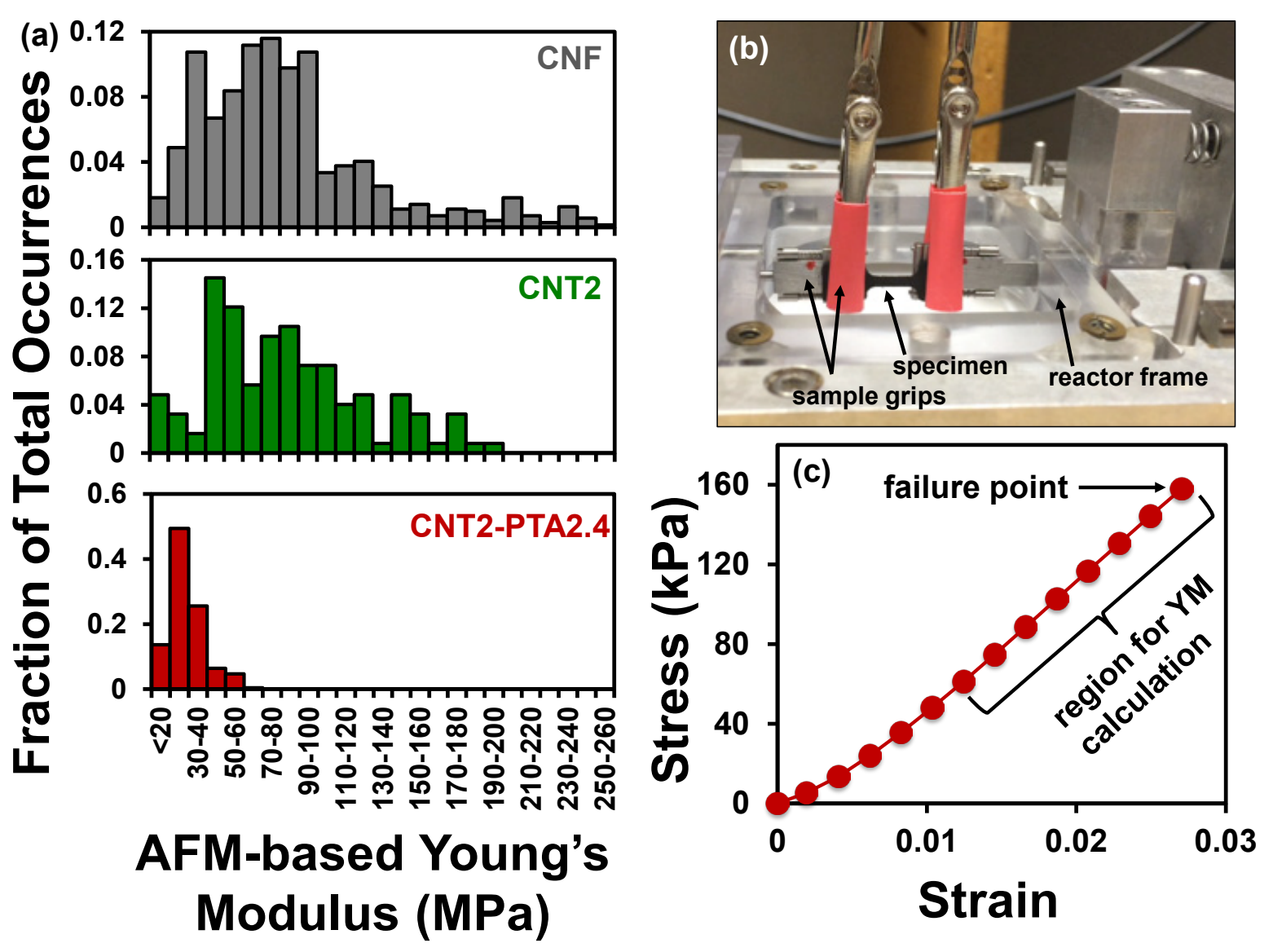

Figure S11. Relevant details of tensile strength testing, including (a) histograms from AFMbased nanoindentation studies to determine Young's Modulus in compression for CNF, CNT2, and CNT2-PTA2.4 materials as indicated. Histograms were developed from 5 sampling locations on 10 individual nanofibers per material. Also shown are the (b) tensile testing device with specimen and (c) a representative stress-strain curve for CNT2-PTA2.4. 


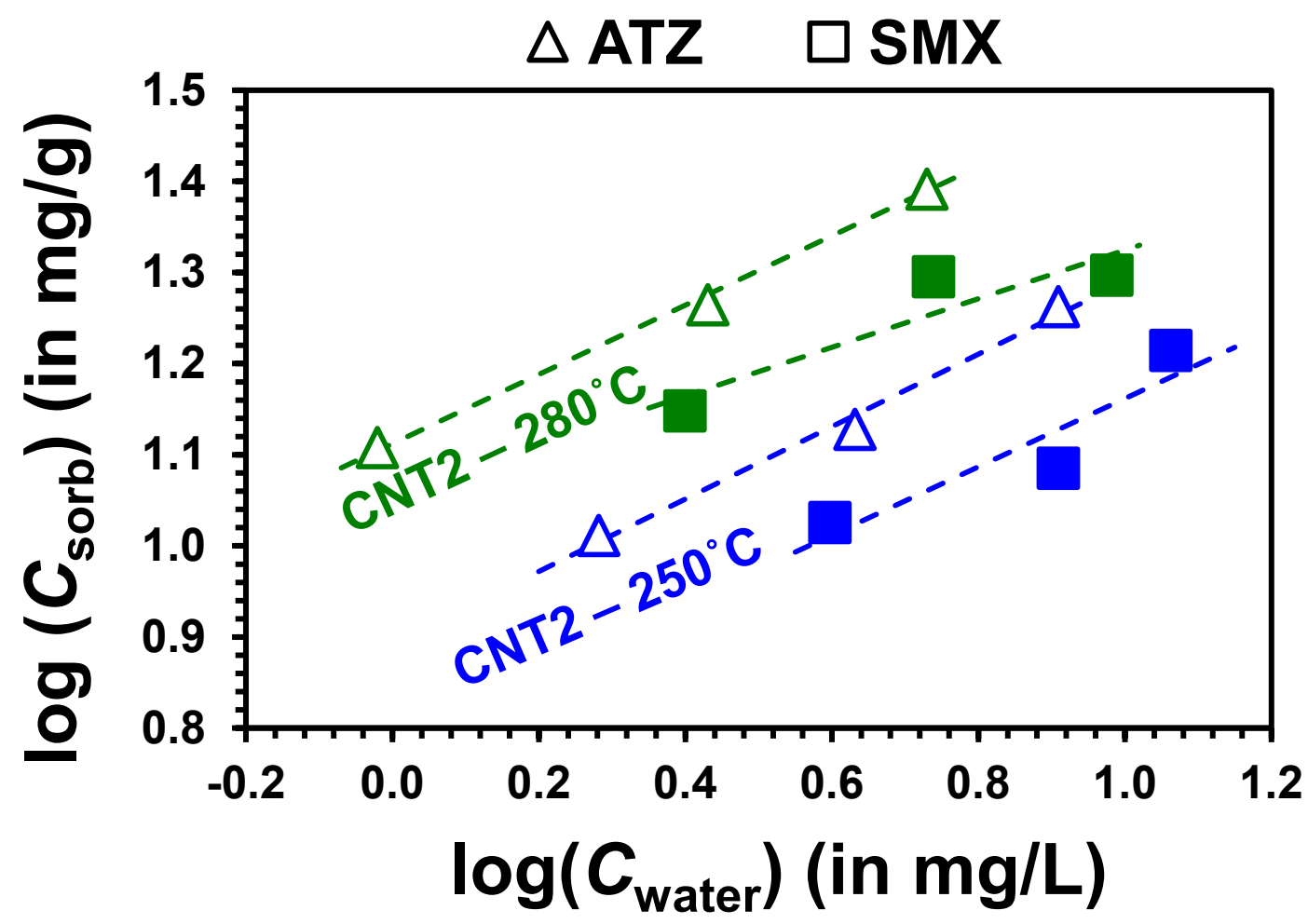

Figure S12. Although a higher degree of oxygenation during thermal stabilization has been shown to improve nanofiber ability to withstand high temperature pyrolysis, ${ }^{15}$ significant differences in material characteristics (e.g., flexibility, ease of handling) were not observed between mats fabricated at the two stabilization temperatures used herein. Sorption isotherms for ATZ and SMX with CNT2 materials stabilized at either $250^{\circ} \mathrm{C}$ (blue) or $280^{\circ} \mathrm{C}$ (green) are shown here. Results consistently showed that a higher stabilization temperature produced higher capacity sorbents, a trend we believe is generalizable across the different composites considered. Thus, stabilization at $280^{\circ} \mathrm{C}$ was used in all other syntheses. Experimental conditions: $0.4 \mathrm{~g} / \mathrm{L}$ sorbent mass loading, $5 \mathrm{mM}$ phosphate buffer, $\mathrm{pH} 7$. 

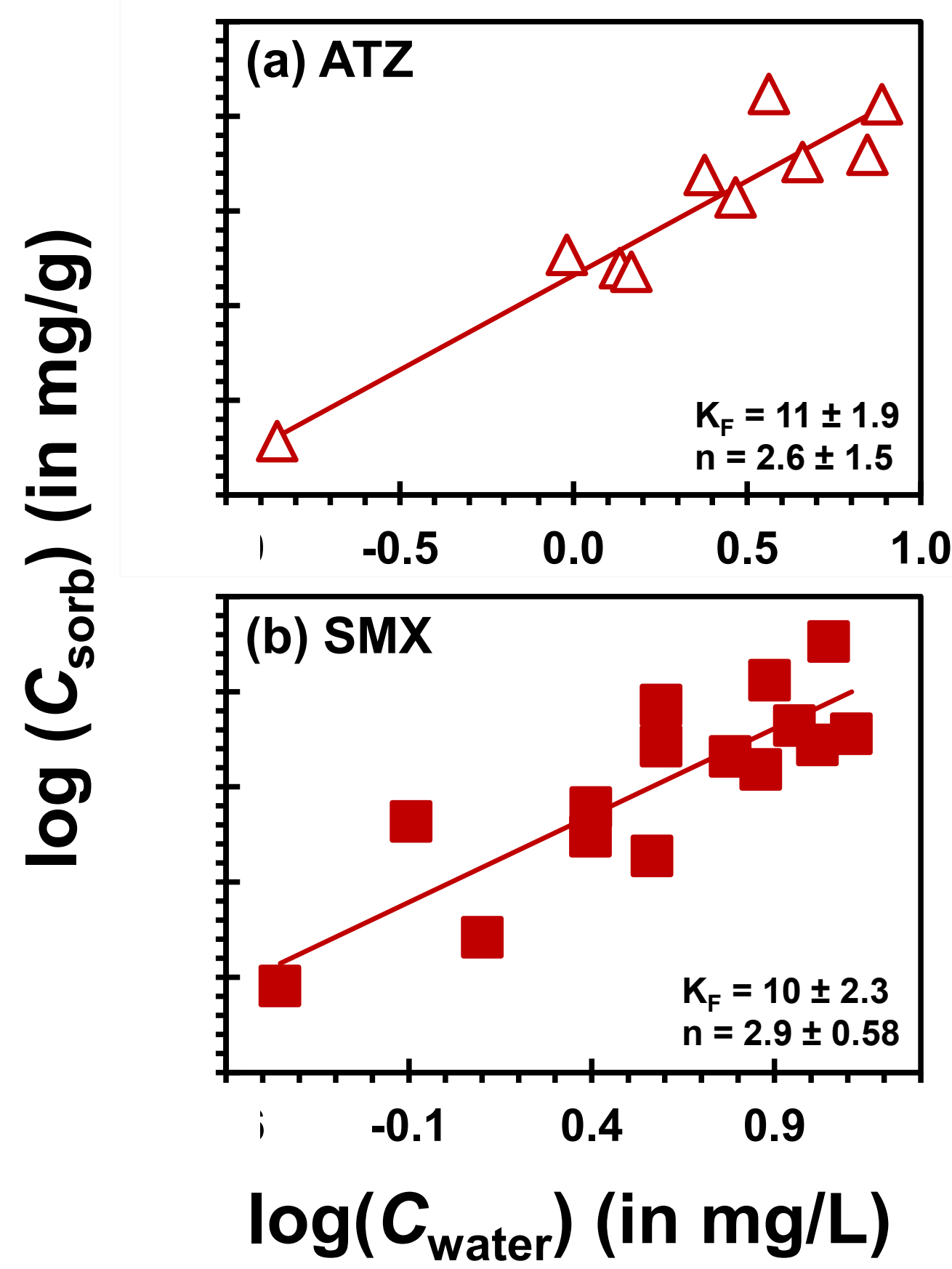

Figure S13. Data from at least triplicate sorption isotherms for (a) ATZ and (b) SMX with CNT2-PTA2.4 materials. Collectively, data is shown from composites fabricated and sorption experiments conducted over the course of a year so as to demonstrate the reproducibility of our methods from material fabrication to application. Linear fits to Freundlich model $\left[\mathrm{C}_{\text {sorbed }}=\right.$ $\mathrm{K}_{\mathrm{f}} \cdot\left(\mathrm{C}_{\text {aqueous }}\right)^{1 / \mathrm{n}}$ ] shown for compiled data, with values for Freundlich parameters based on fits for individual isotherms. Experimental conditions: $0.4 \mathrm{~g} / \mathrm{L}$ sorbent mass loading, $5 \mathrm{mM}$ phosphate buffer, $\mathrm{pH} 7$. 


\section{$\triangle \mathrm{ATZ} \quad \square \mathrm{SMX}$}

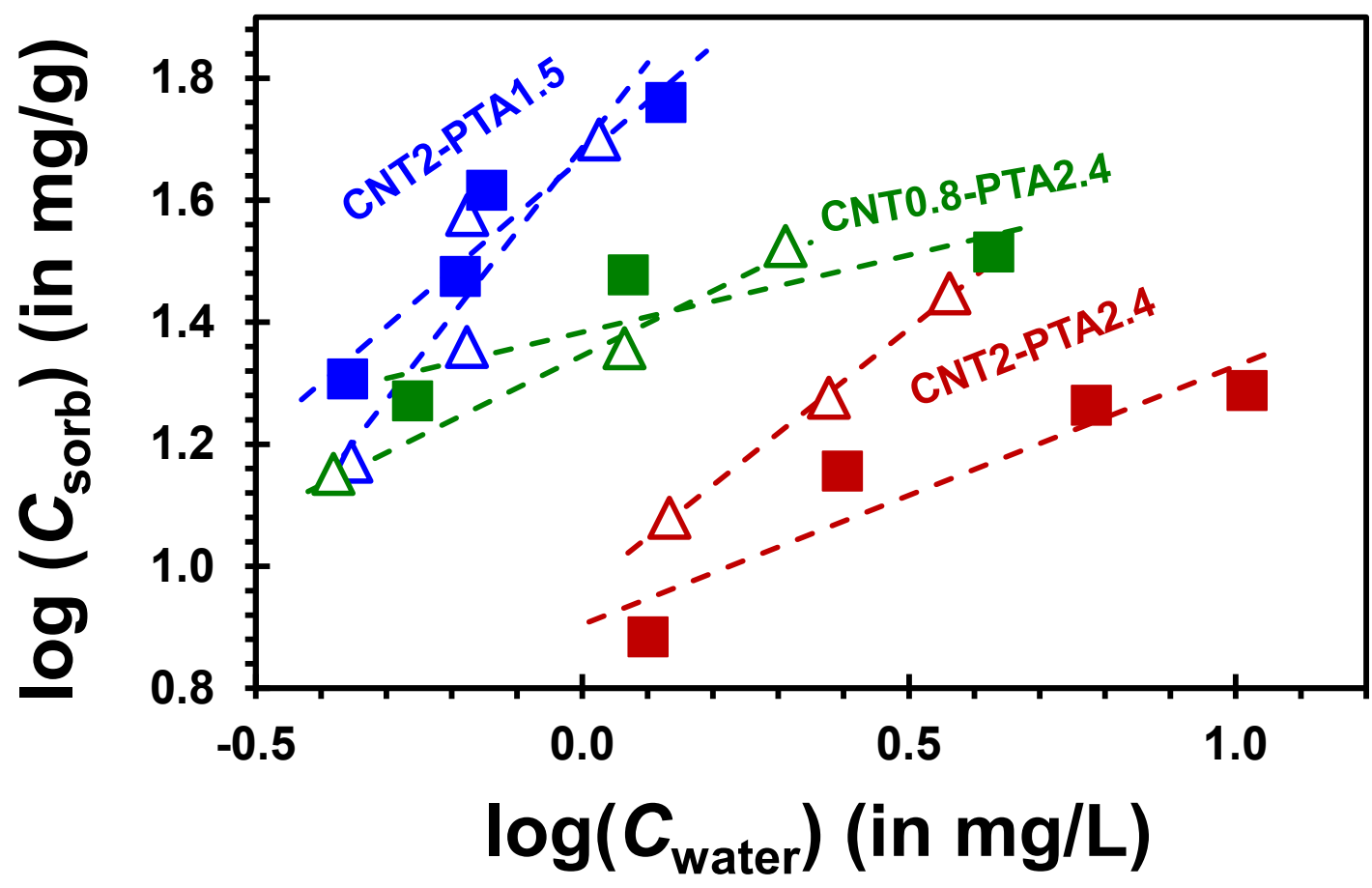

Figure S14. Comparison of sorption isotherms for ATZ and SMX obtained with the optimal composite formulation CNT2-PTA2.4 (considering strength and reactivity) to CNT0.8-PTA2.4 and CNT2-PTA1.5, alternative formulations found to be weaker during material testing. Notably, CNT0.8-PTA2.4 and CNT2-PTA1.5 showed approximately equivalent capacity for ATZ and SMX (i.e., sorbent performance was independent of sorbate hydrophobicity). Trends in ATZ and SMX uptake for these materials illustrate that increasing CNTs and macroporosity promote sorption. However, too much macroporosity ultimately yields weaker nanofibers that are more prone to fracture. Thus, in design of these composites, there exists an optimal macroposity (i.e., PTA loading), a value that increases surface area and access to embedded CNTs while not compromising composite strength. Experimental conditions: $0.4 \mathrm{~g} / \mathrm{L}$ sorbent mass loading, $5 \mathrm{mM}$ phosphate buffer, $\mathrm{pH} 7$. 


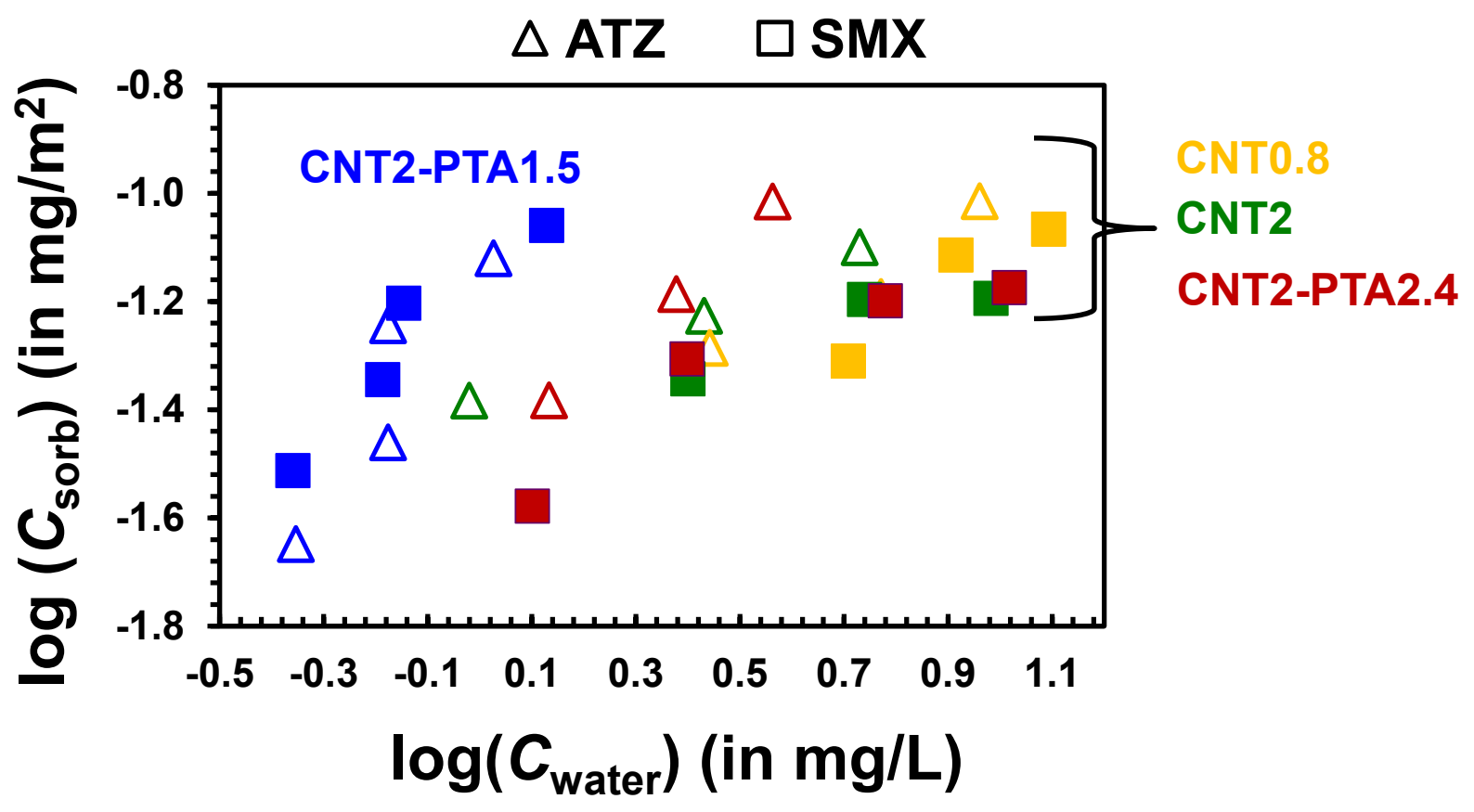

Figure S15. Sorption isotherms for ATZ and SMX with CNT0.8, CNT2, CNT2-PTA2.4, and CNT2-PTA1.5 when sorbed concentrations are normalized to measured $\mathrm{N}_{2}$-BET surface area. Generally, the relative performance of all sorbent materials except CNT2-PTA1.5 can be rationalized by the materials' relative differences in reactive surface area. Accordingly, normalization to surface area shows similar sorption behavior for CNT0.8, CNT2 and CNT2PTA2.4. For CNT2-PTA1.5, the greater uptake of ATZ and SMX, even after accounting for available surface area, suggests there may be uniquely reactive surface sites on these materials that promote micropollutant uptake. Experimental conditions: $0.4 \mathrm{~g} / \mathrm{L}$ sorbent mass loading, 5 $\mathrm{mM}$ phosphate buffer, $\mathrm{pH} 7$. 

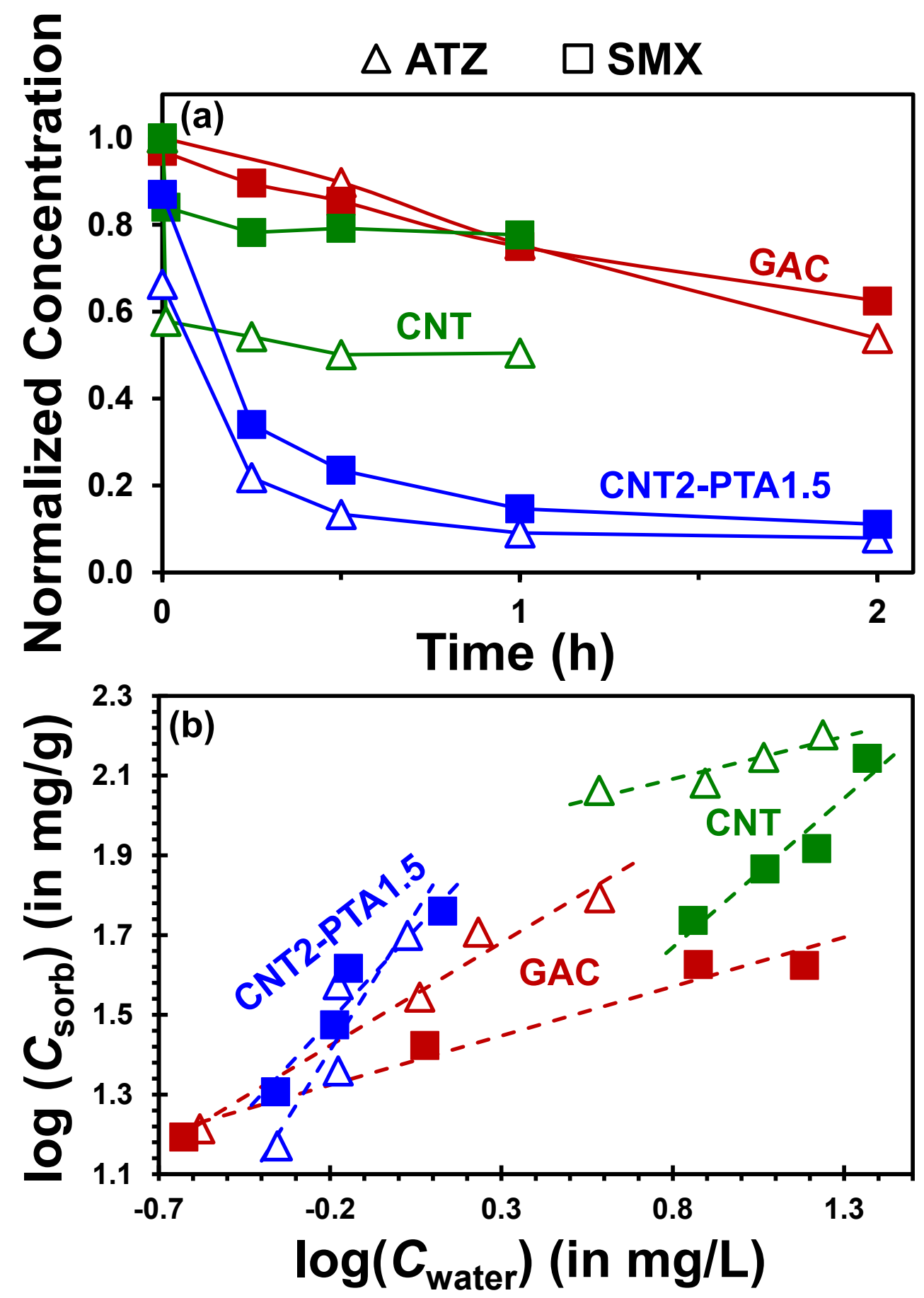

Figure S16. Performance comparison for CNT2-PTA1.5 (the highest capacity nanofiber material) relative to GAC and CNTs, including sorption (a) kinetics and (b) isotherm experiments. Although CNT2-PTA1.5 exhibited faster kinetics and comparable sorption capacities relative to GAC, material strength considerations (i.e., weak, falls apart upon handling) prevent practical application of the material. Experimental conditions: kinetics - 0.5 $\mathrm{g} / \mathrm{L}$ sorbent mass loading, $5 \mathrm{mM}$ phosphate buffer, $\mathrm{pH}$ 7, $70 \mu \mathrm{M}$ initial concentration; isotherms $-0.4 \mathrm{~g} / \mathrm{L}$ sorbent mass loading, $5 \mathrm{mM}$ phosphate buffer, $\mathrm{pH} 7$. 


\section{$\triangle \mathrm{ATZ} \quad \square \mathrm{SMX}$}
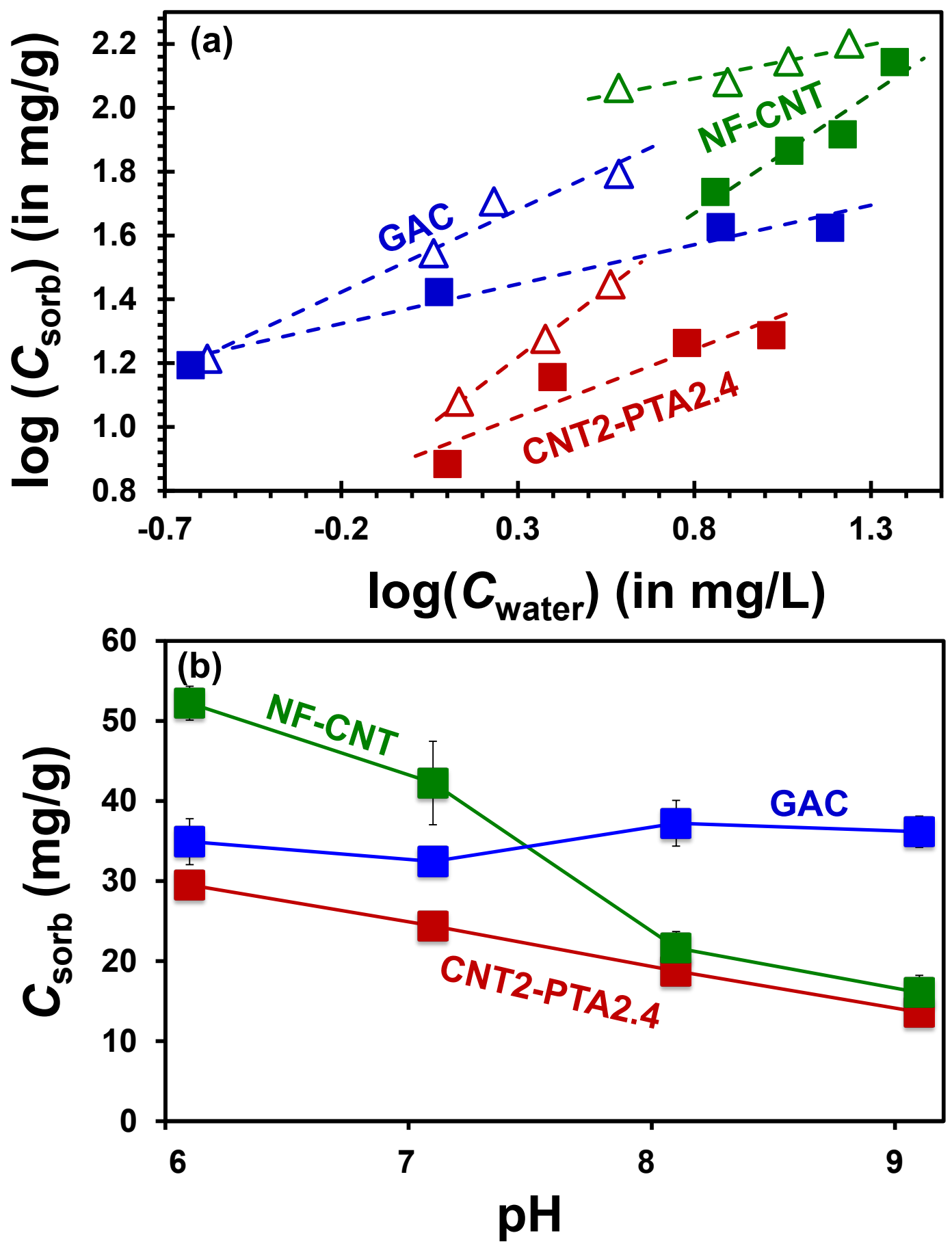

Figure S17. Mass-normalized performance comparison for CNT2-PTA2.4 relative to GAC and CNTs, including (a) sorption isotherms for ATZ and SMX (pH 7) and (b) SMX sorption as a function of $\mathrm{pH}$ (i.e., $\mathrm{pH}$-edge behavior at an initial SMX concentration of $70 \mu \mathrm{M}$ ). Experimental conditions: $0.4 \mathrm{~g} / \mathrm{L}$ sorbent mass loading, $5 \mathrm{mM}$ phosphate buffer. 


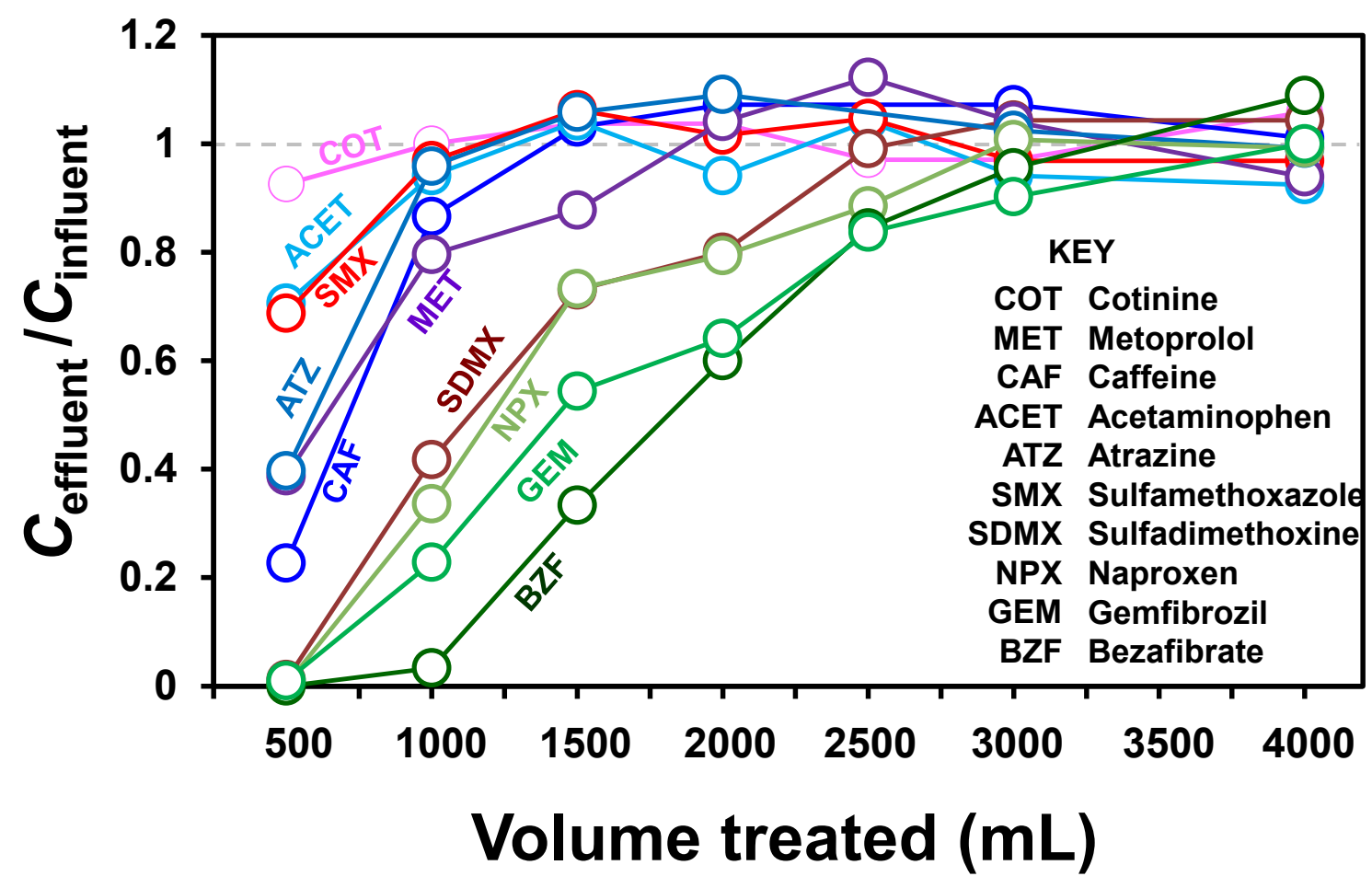

Figure S18. Breakthrough curves from multi-contaminant (5 $\mu \mathrm{g} / \mathrm{L}$ each) flow-through experiments in a matrix more representative of natural waters ( $1 \mathrm{mM}$ carbonate buffer, $\mathrm{pH} 7)$. Performance trends echo those observed in the deionized water systems, albeit with breakthrough consistently occurring at smaller volumes of treated influent (consistent with competition for sorption sites from dissolved carbonate species). Experimental conditions: 47$\mathrm{mm}$ (9.6 $\mathrm{cm}^{2}$ active area), $14 \mathrm{mg}$ CNT2-PTA2.4 filter supported by $47-\mathrm{mm} 1.2 \mu \mathrm{m}$ glass fiber filter; flux $1000 \mathrm{LMH}$; gravity-fed. 


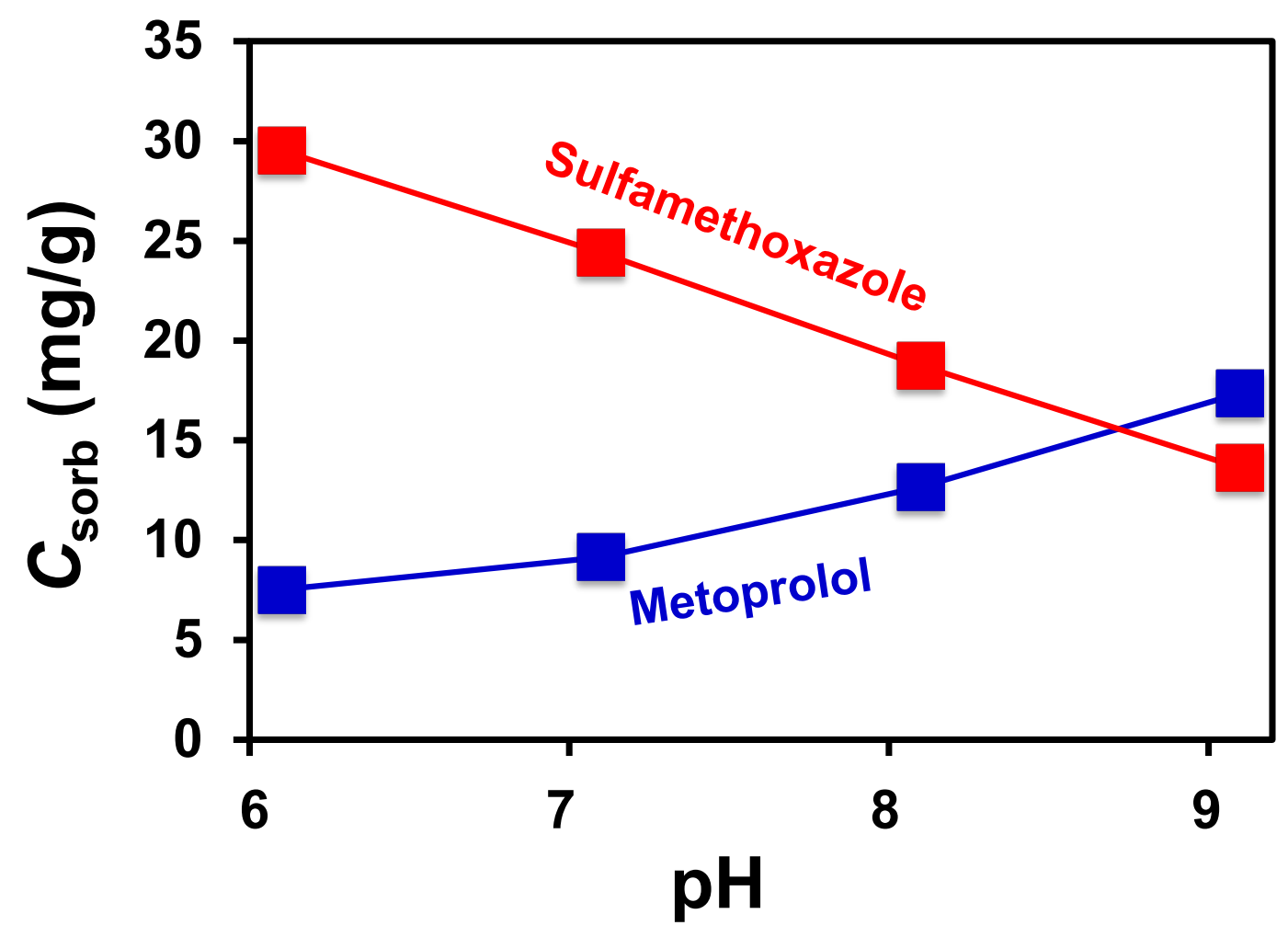

Figure S19. SMX (p $K_{\mathrm{a}}$ 9.28) and metoprolol ( $K_{\mathrm{a}}$ 9.09) sorption on CNT2-PTA2.4 as a function of $\mathrm{pH}$. Removal of each compound decreases with the increasing fraction of anionic species (e.g., SMX at higher $\mathrm{pH}$ ) or cationic species (e.g., metoprolol at lower $\mathrm{pH}$ ). Experimental conditions: $0.4 \mathrm{~g} / \mathrm{L}$ sorbent mass loading, $5 \mathrm{mM}$ phosphate buffer, $70 \mu \mathrm{M}$ initial concentration. 


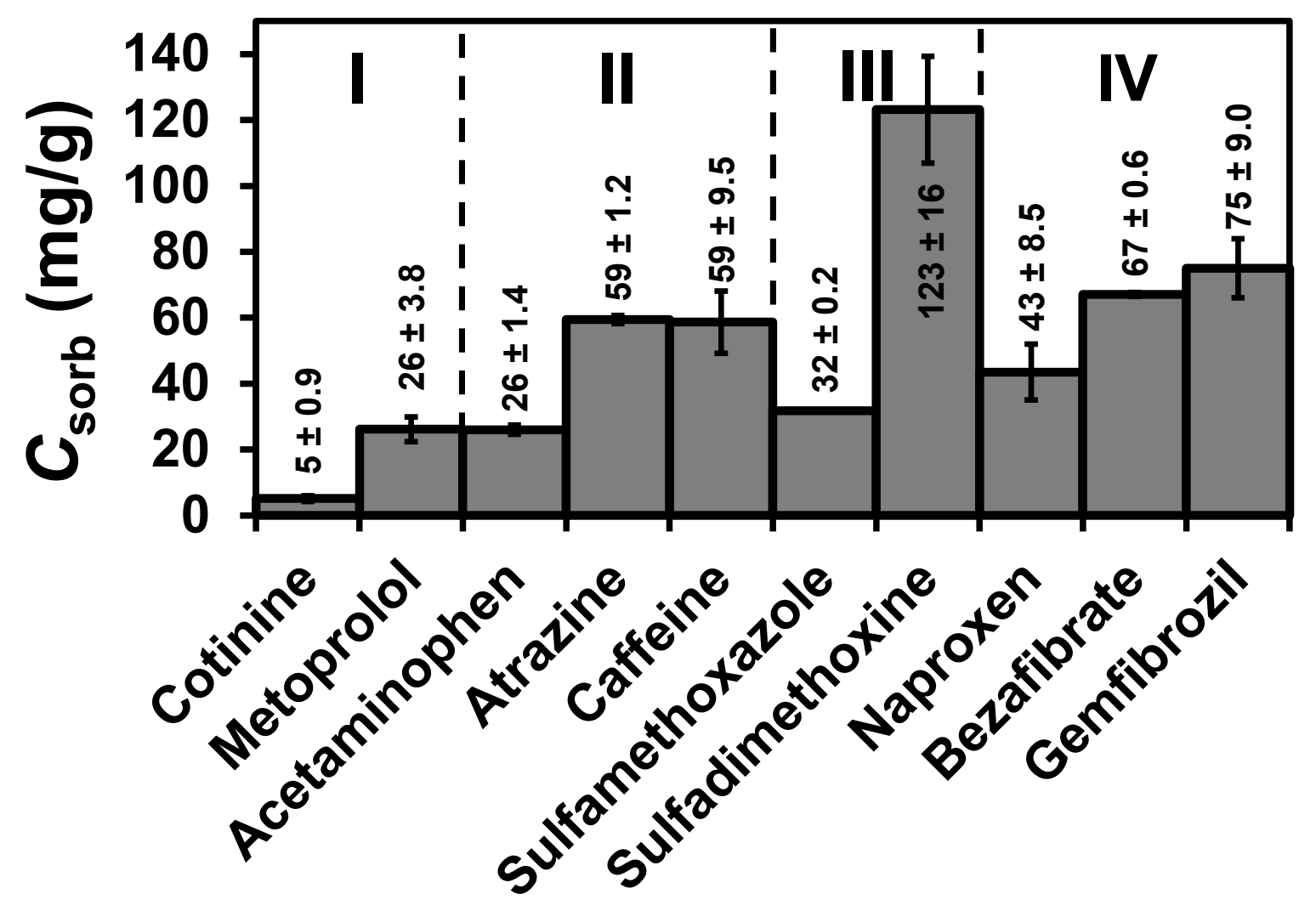

Figure S20. Single-point sorption uptake results for removal of the 10-compound suite of micropollutants on dispersed CNTs. Results roughly match the trends for pollutant breakthrough observed in the multi-contaminant flow-through systems (see Figure 5 in the main text). Group designations (I-IV) indicate relative removal classes in multi-contaminant flow-through system, as discussed in the main text and described as follows: Group I - Compounds essentially unretained; Group II - Compounds for which moderate removal was observed; Group III Compounds for which good removal was observed (sulfa drugs); Group IV - Compounds for which $>95 \%$ removal was observed (hydrophobic compounds). Experimental conditions: CNT mass loading $0.06 \mathrm{~g} / \mathrm{L}, 50 \mu \mathrm{M}$ initial concentration, $5 \mathrm{mM}$ phosphate buffer, $\mathrm{pH} 7$. 


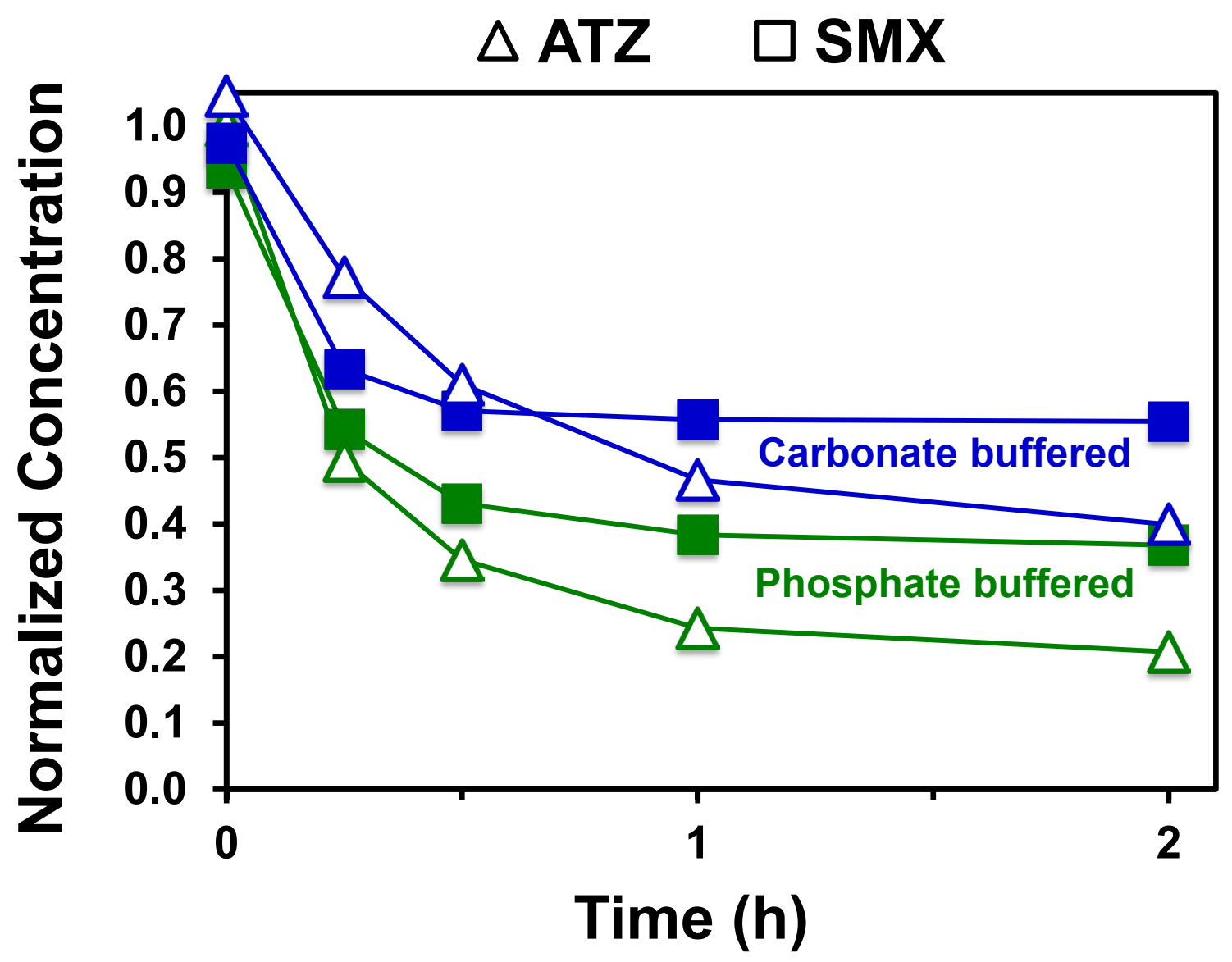

Figure S21. Effect of dissolved carbonate species on sorption of SMX (squares) and ATZ (triangles) on CNT2-PTA2.4 (data in blue). Data (in green) from a phosphate buffered system are provided for comparison. Diminished sorption of both SMX and ATZ in the carbonate buffered system likely indicates an inhibitory role for dissolved carbonate via competition for available sorption sites. Experimental conditions: $0.4 \mathrm{~g} / \mathrm{L}$ sorbent mass loading, $50 \mu \mathrm{M}$ initial concentration, $\mathrm{pH}$ 7, either $5 \mathrm{mM}$ phosphate buffer or $1 \mathrm{mM}$ carbonate buffer. 


\section{Literature Cited}

(1) Verdugo, E. M.; Krause, C.; Genskow, K.; Han, Y.; Baltrusaitis, J.; Mattes, T. E.; Valentine, R. L.; Cwiertny, D. M. N-Functionalized Carbon Nanotubes As a Source and Precursor of $N$-Nitrosodimethylamine: Implications for Environmental Fate, Transport, and Toxicity. Environ. Sci. Technol. 2014, 48 (16), 9279-9287.

(2) Baltrusaitis, J.; Usher, C. R.; Grassian, V. H. Reactions of Sulfur Dioxide on Calcium Carbonate Single Crystal and Particle Surfaces at the Adsorbed Water Carbonate Interface. Phys. Chem. Chem. Phys. 2007, 9 (23), 3011.

(3) Karunatilaka, C.; Bučar, D.-K.; Ditzler, L. R.; Friščić, T.; Swenson, D. C.; MacGillivray, L. R.; Tivanski, A. V. Softening and Hardening of Macro- and Nano-Sized Organic Cocrystals in a Single-Crystal Transformation. Angew. Chem. Int. Ed. 2011, 50 (37), 8642-8646.

(4) Hutchins, K. M.; Rupasinghe, T. P.; Ditzler, L. R.; Swenson, D. C.; Sander, J. R. G.; Baltrusaitis, J.; Tivanski, A. V.; MacGillivray, L. R. Nanocrystals of a Metal-Organic Complex Exhibit Remarkably High Conductivity That Increases in a Single-Crystal-toSingle-Crystal Transformation. J. Am. Chem. Soc. 2014, 136 (19), 6778-6781.

(5) Guo, S.; Akhremitchev, B. B. Investigation of Mechanical Properties of Insulin Crystals by Atomic Force Microscopy. Langmuir 2008, 24 (3), 880-887.

(6) Hutter, J. L.; Bechhoefer, J. Calibration of Atomic-Force Microscope Tips. Rev. Sci. Instrum. 1993, 64 (7), 1868.

(7) Guo, J.-G.; Zhao, Y.-P. The Size-Dependent Elastic Properties of Nanofilms with Surface Effects. J. Appl. Phys. 2005, 98 (7), 074306.

(8) Hertz, H. On the Contact of Elastic Solids. J. Für Reine Angew. Math. 1881, 92 (110), $156-171$.

(9) Johnson, K. L. Contact Mechanics; Cambridge University Press, 1987.

(10) Dolati, F.; Yu, Y.; Zhang, Y.; Jesus, A. M. D.; Sander, E. A.; Ozbolat, I. T. In Vitro Evaluation of Carbon-Nanotube-Reinforced Bioprintable Vascular Conduits. Nanotechnology 2014, 25 (14), 145101.

(11) Royal Society of Chemistry. ChemSpider http://www.chemspider.com/.

(12) SPARC http://archemcalc.com/sparc-web/calc.

(13) Liu, H.; Cao, C.-Y.; Wei, F.-F.; Huang, P.-P.; Sun, Y.-B.; Jiang, L.; Song, W.-G. Flexible Macroporous Carbon Nanofiber Film with High Oil Adsorption Capacity. J. Mater. Chem. A 2014, 2 (10), 3557.

(14) Huang, L.; Bui, N.-N.; Manickam, S. S.; McCutcheon, J. R. Controlling Electrospun Nanofiber Morphology and Mechanical Properties Using Humidity. J. Polym. Sci. Part B Polym. Phys. 2011, 49 (24), 1734-1744.

(15) Rahaman, M. S. A.; Ismail, A. F.; Mustafa, A. A Review of Heat Treatment on Polyacrylonitrile Fiber. Polym. Degrad. Stab. 2007, 92 (8), 1421-1432.

(16) Wu, M.; Wang, Q.; Li, K.; Wu, Y.; Liu, H. Optimization of Stabilization Conditions for Electrospun Polyacrylonitrile Nanofibers. Polym. Degrad. Stab. 2012, 97 (8), 1511-1519. 